\title{
Josef Hejnic
}

\section{Bohemikale Drucke \\ des 16.-18. Jahrhunderts}

Verlag Otto Sagner München · Berlin - Washington D.C.

Digitalisiert im Rahmen der Kooperation mit dem DFG-Projekt „Digi20“

der Bayerischen Staatsbibliothek, München. OCR-Bearbeitung und Erstellung des eBooks durch den Verlag Otto Sagner:

http://verlag.kubon-sagner.de

() bei Verlag Otto Sagner. Eine Verwertung oder Weitergabe der Texte und Abbildungen, insbesondere durch Vervielfältigung, ist ohne vorherige schriftliche Genehmigung des Verlages unzulässig.

«Verlag Otto Sagner» ist ein Imprint der Kubon \& Sagner $\mathrm{GmbH}_{\text {Josef Hejnic - } 9783954794034}$ 
Die Druckvorlage wurde erstellt von

Steffi Kutschke

Bayerlsche
Staatsbibliothek

ISBN 3-87690-440-4

(C)

by Verlag Otto Sagner, München 1990.

Abteilung der Firma Kubon und Sagner,

Buchexport/import GmbH München

Offsetdruck: Kurt Urlaub, Bamberg 
Vorträge und Abhandlungen

zur

Slavistik

herausgegeben von Peter Thiergen (Bamberg)

Band 17 


\section{$\therefore$ er if

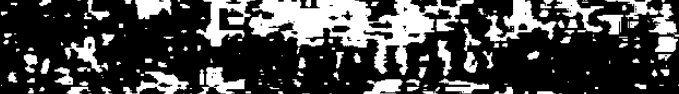

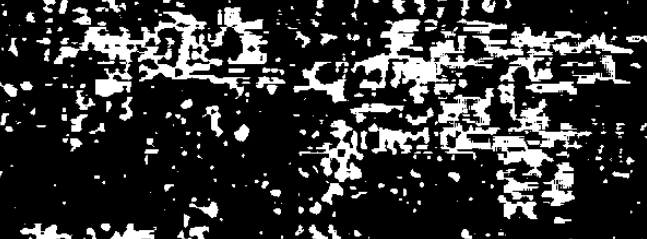

The

f5 ref

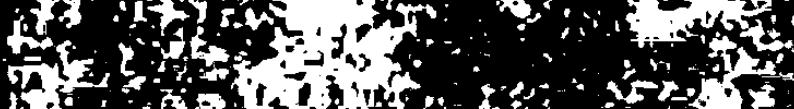

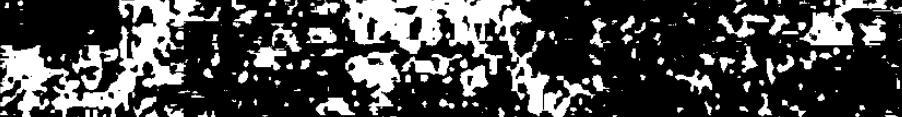

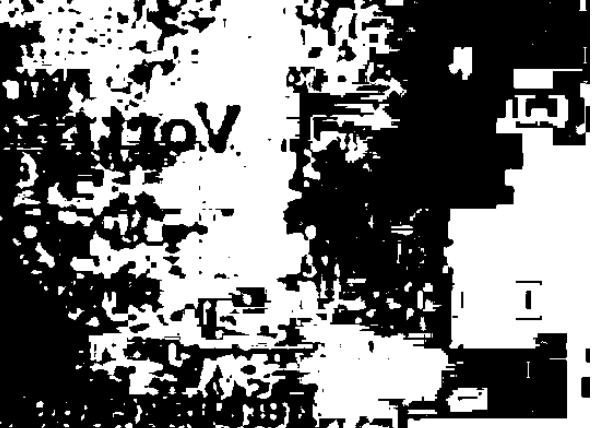

Enistas

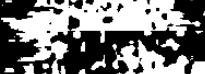

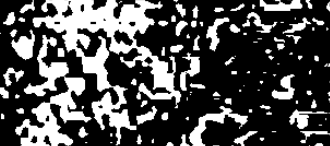

Anting

lif

at of

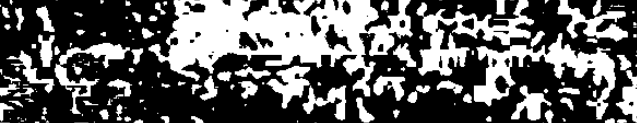

Alond

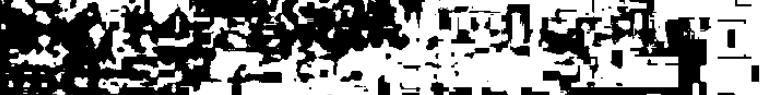

minges wat to

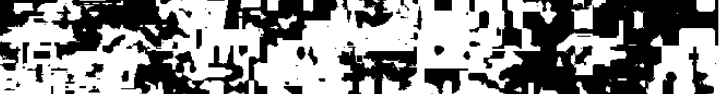




\section{FRAGEN DER}

\section{BIBLIOGRAPHISCHEN BESCHREIBUNG \\ UND BEARBEITUNG}

DER TSCHECHISCHEN UND

FREMDSPRACHIGEN

BOHEMIKALEN DRUCKE

DES 16. - 18. JAHRHUNDERTS

von

Josef Hejnic unter Mitwirkung von

Anežka Badurová und Mirjam Bohatcová 


\section{Inhaltsverzeichnis}

Fragen der bibliographischen Beschreibung und Bearbeitung der tsichechischen und fremdsprachigen bohemikalen Drucke

Ziele der weiteren Forschung

Bibliographische Beilage

Zusarnmengestellt von Anežka Badurová

Deutsche Übersetzung: Hildegard Boková und Václav Bok 


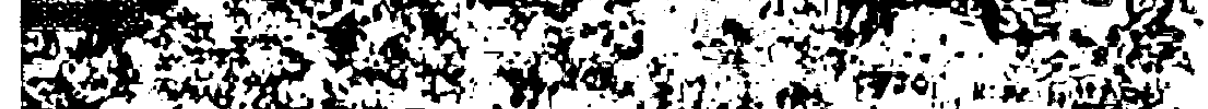

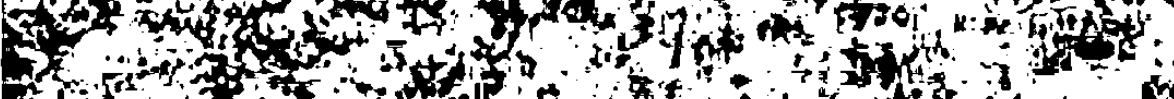

and

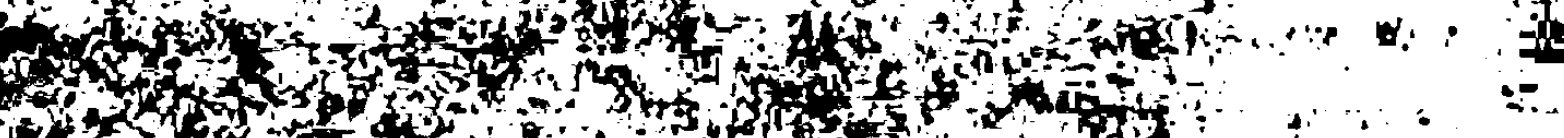

Fis

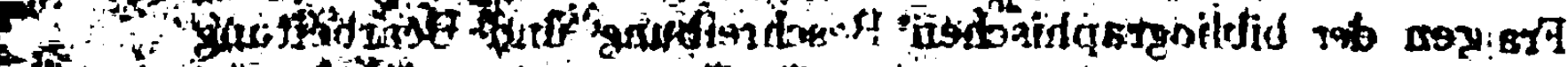

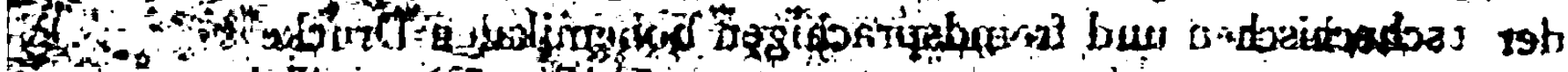

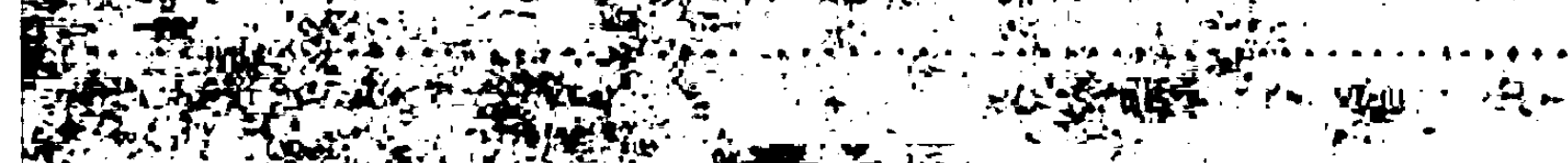

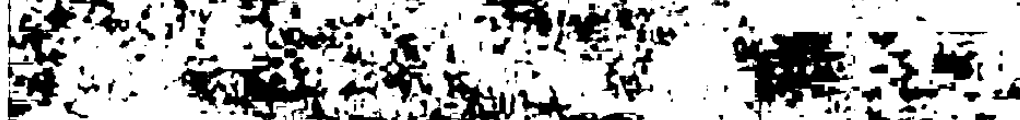

int

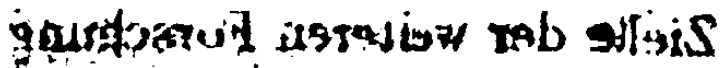

tro

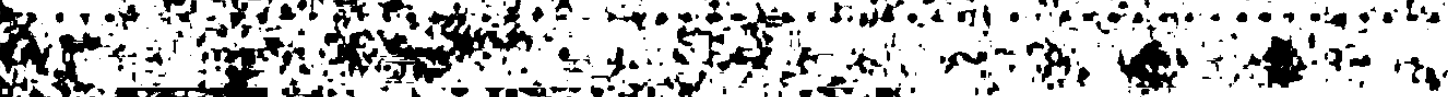

Ho

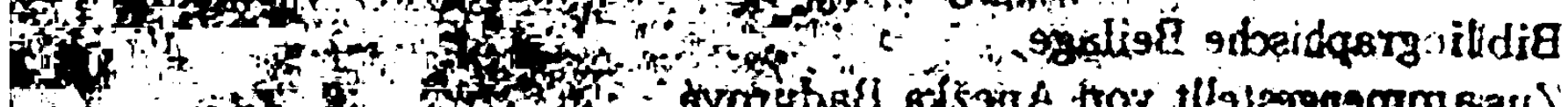

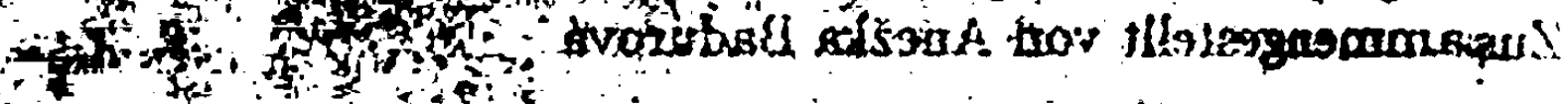

Fan

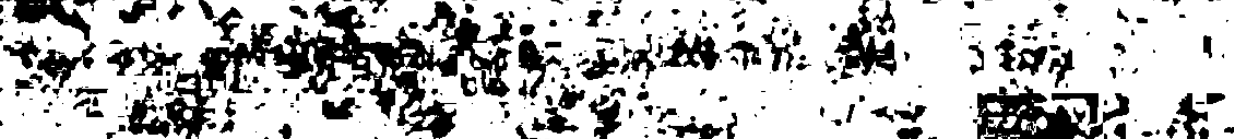

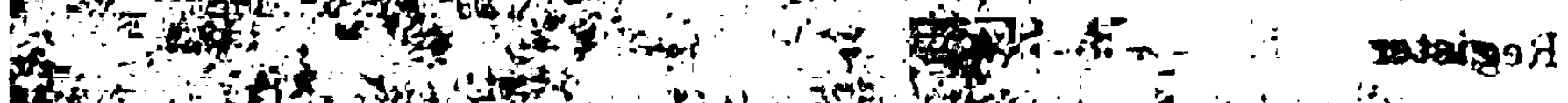

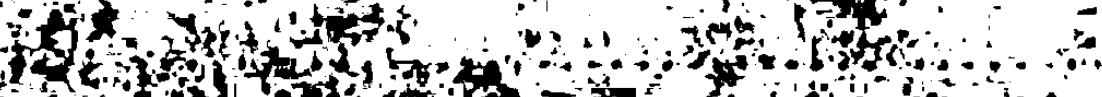
?.

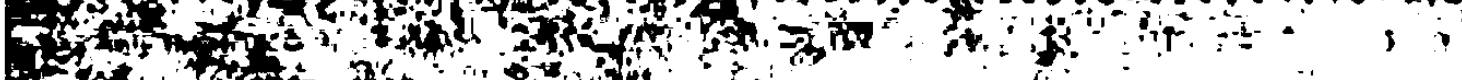

s.

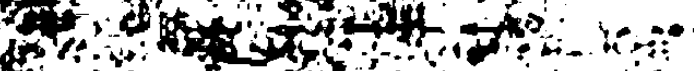

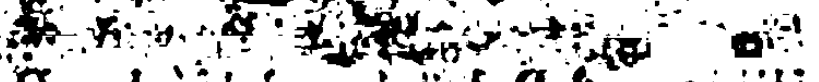

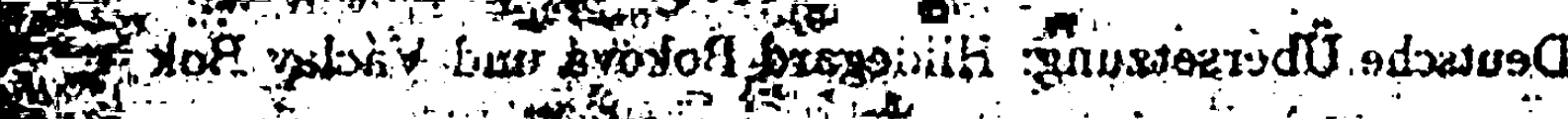

thetion

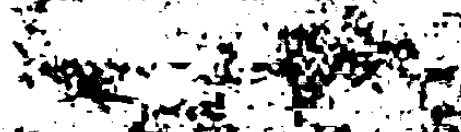

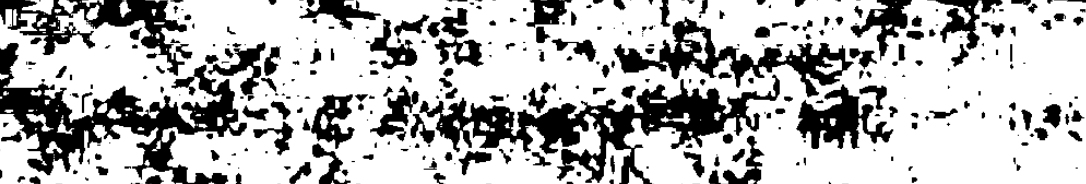

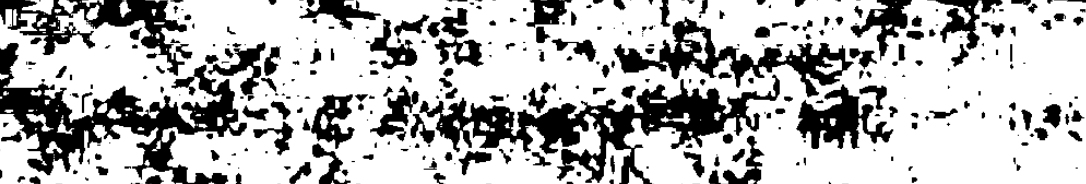

Anto

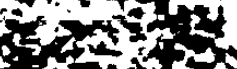

intatis

$+5$

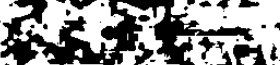

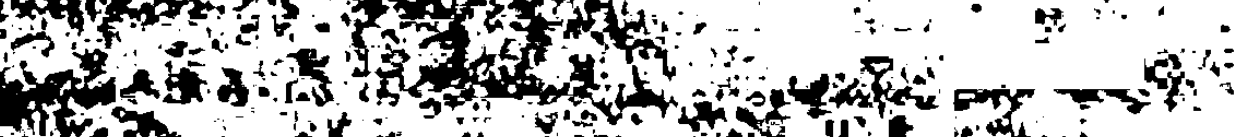

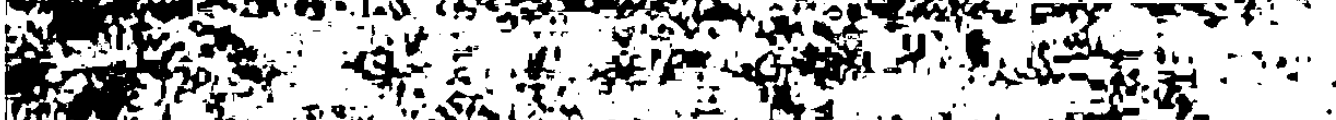

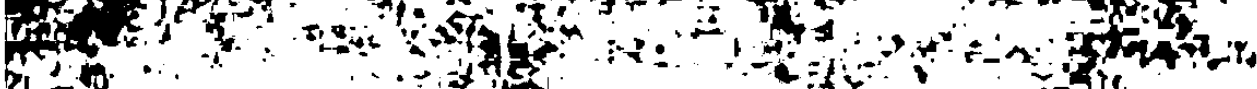

tidi

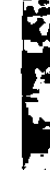

of

(t)

and ont

PA: : $=0$

Fì

Sol

.

Sol

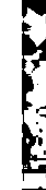

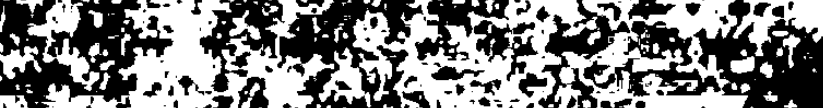
istion

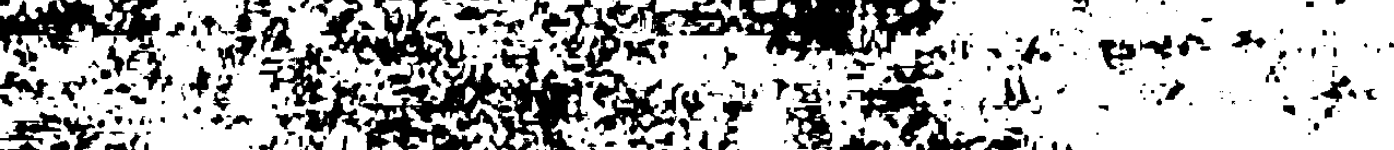

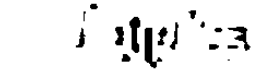

=

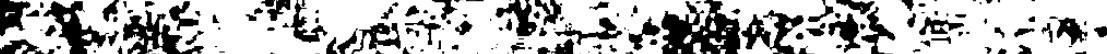

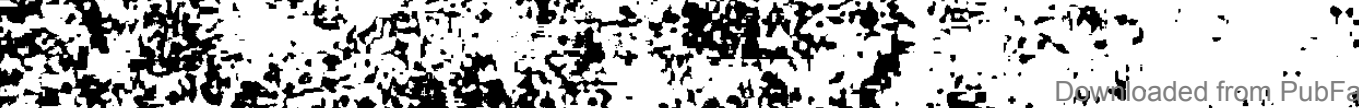

Hor

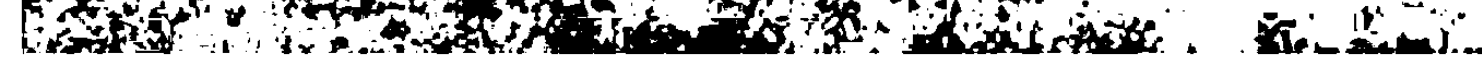

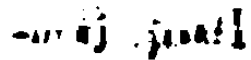

? ininbs

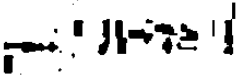




\section{Fragen}

\section{der bibliographischen Beschreibung}

\section{und Bearbeitung}

\section{der tschechischen und fremdsprachigen \\ bohemikalen Drucke des 16.-18. Jahrhunderts}

(Bisherige Ergebnisse und Ziele der weiteren Forschung)

Im Mittelalter wurden in den Ländern der Böhmischen Krone für literarische Äußerungen wie das Tschechische, so auch Fremdsprachen verwendet ${ }^{1}$. Das literarische Leben wurde durch die Gründung der Karlsuniversität im Jahre 1348 auf eine höhere Stufe gehoben. Im 15. Jahrhundert, im Rahmen der gesamteuropäischen Durchsetzung der Nationalsprachen, die in Böhmen und Mähren durch die Forderung der Hussiten verstärkt wurde, daß besonders das gepredigte Wort allgemein verständlich sein müsse, kam es zu einer beträchtlichen Erweiterung der in Tschechisch tradierten Literatur, und das Tschechische behielt seine dominante Stellung in Böhmen und Mähren auch nach der Einführung des Buchdrucks. Die fremdsprachig gedruckte Literatur, besonders die lateinische und weniger die deutsche, verbreitete sich im Rahmen des böhmischen Staates wesentlich seit der Mitte des 16. Jahrhunderts dank der Entfaltung des städtischen Schulwesens und der wissenschaftlichen Bestrebungen, der Einwirkung der deutschen und schweizerischen Reformation, später auch dank der definitiven Übersiedlung (seit 1583) des Hofes Kaiser Rudolfs II. nach Prag sowie dank den intensiveren offziellen und privaten Kontakte mit näheren und entfernteren Regionen. Diese Tendenz vertiefte sich

1 Mit dem Terminus fremdsprachige bohemikale Drucke bezeichnen wir hi.er diejenigen Werke, in denen antike, germanische, romanische und slawische Sprachen verwendet wurden, soweit sie in den Ländern der Böhmischen Krone herausgegeben wurden (Böhmen, Mähren; Ober- und Niederlausitz bis 1635; $O$ ber- und Niederschlesien mit dem Glatzer Gebiet bis 1742). Von den im A usland herausgegebenen Schriften beschränken wir uns auf die Werke der A utoren, die von dem Königreich Böhmen stammten, und auf die Werke, die in dem böhmischen Staat nachweislich entstanden sind. 
dann, allerdings aus völlig anderen Gründen (Ende des ständischen Staates), nach dem Jahre 1620.

Zuerst war während des Dreißigjährigen Krieges (16181648) im kulturellen Leben der Aufstieg von fremden Sprachen nicht allzusehr sichtbar, aber in der zweiten Hälfte des 17. Jahrhunderts, die eine Zeit der Erneuerung war, zeigten sich bereits die Folgen eines relativ hohen Populationswechsels (Weggang von Nichtkatholiken und Zufluß von Ausländern) sowie der erhöhten Einwirkung des in der absolutistischen habsburgischen Monarchie in Deutsch geführten Verwaltungsapparats. Die Gymnasien und die beiden Universitäten (Prag und Olmütz) wurden von den Jesuiten beherrscht, die Latein bevorzugten. In dieser Sprache wurden auch die bedeutendsten Werke der Exulanten aus Böhmen und Mähren geschrieben, die im Ausland erschienen (Comenius, Stránský). Zugleich stieg in beträchtlichem Maße in quantitativer und qualitativer Hinsicht die Bedeutung der deutsch geschriebenen Literatur ${ }^{2}$.

Den ersten systematischen, wenn auch zeitlich begrenzten Versuch einer Zusammenstellung der bohemikalen fremdsprachigen Fachliteratur innerhalb des europäischen Kontextes brachten die Schweizer Bibliographen Konrad Gesner ( $†$ 1565) und seine Fortsetzer Iosias Simler ( $\dagger$ 1576) und Ioannes Iacobus Frisius ( $\dagger 1611)$ im Werk Bibliotheca universalis, das zum ersten Mal 1545, zum letzten Mal in erweiterter und von Simler und Frisius umgearbeiteter Fassung im Jahre 1583, jeweils in Zürich, erschienen ist. Die Schweizer Bibliographen führten (außer Lusatica und Silesiaca) gegen 270 fremdsprachige Bohemica an, die sie teilweise aus Autopsie, teilweise mittelbar kannten. Ihr bibliographisches Werk wurde in Böhmen (z.B. an der Karlsuniversität) schnell heimisch und fand bald - wenn auch in anderer Form - seine Fortsetzer in Prokop Lupác ( $\dagger$ 1587) und Daniel Adam von Veleslavín ( $†$ 1599), aber erst in der zweiteu Hälfte des 17. Jahrhunderts wurden diese Teilversuche der Professoren der Prager utraquistischen Universität durch das Werk Bohemia docta von Bohuslav Balbín ( $†$ 1688) überboten, das jedoch erst in den Jahren 1776-80 (Knihopis, Nr. 939-940) herausgegeben wurde ${ }^{3}$.

2 In der Verneuerten Landesordnung (in Böhmen 1627, in Mähren 1628) wurde das Deutsche als Amtssprache auf das Niveau des Tschechischen gestelli.

3 Josef Hejnic - Václav Bok, Gesners europäische Bibliographie und 
Balbíns Beispiel folgte Jan Jiří Středovský († 1713), dessen unvollendetes Werk Brevis Memoria Moravorum Scriptorum von den Bibliographen des 19. Jh. und von Knihopis ausgenutzt wurde. Analoge Versuche einer retrospektiven $\mathrm{Zu}$ sammenstellung der bohemikalen Literatur realisierten nacheinander Magnoald Ziegelbauer ( $\dagger$ 1750), Bonaventura Josef Pitter $(\dagger 1764)$ und Bernard Erber ( $\dagger$ 1773), wobei lediglich Erbers Werk Notitia illustris Regni Bohemiae Scriptorum aus dem Jahre 1760 in gedruckter Form einer breiteren Öffentlichkeit diente. An der Wende des 18. zum 19. Jahrhundert knüpften an diese bibliographischen Bemühungen Josef Dobrovský (1753-1829) und seine Zeitgenossen Mikuláš Voigt (Adauctus a S. Germano, † 1787), František Martin Pelcl ( $\dagger$ 1801), Karel Rafael Ungar ( $\dagger$ 1807), Jiř́ Ribay ( $†$ 1812), Jan Bohumír Dlabač ( $\dagger$ 1820) und weitere an; durch eine systematische Arbeit ragte der mährische Sammler Jan Petr Cerroni ( $\dagger$ 1826) hervor, der ein bio-bibliographisches Lexikon anlegte (Staatsarchiv Brno: G 12), das ohne Berücksichtigung der sprachlichen Seite der literarischen Werke (tschechische und fremdsprachige Werke) und ohne Berücksichtigung der Form (Drucke und Handschriften) bearbeitet wurde. Bibliographische Eintragungen in den genannten Studien und Zusammenstellungen des 17 . bis beginnenden 19. Jahrhunderts setzten die von den Schweizer Bibliographen begründete Tradition fort (es werden Format, Druckort, manchmal auch Drucker, Erscheinungsjahr, Anzahl der Seiten, Blätter oder Lagen angegeben, $a b$ und $z u$ wird auch über den Inhalt des Werkes oder über seinen Aufbewahrungsort gesprochen). Diese Bibliographien ermöglichen die Identifizierung der literarischen Werke, aber sie selbst blieben meistens im Manuskript ${ }^{4}$.

Die Stellung der Ober- und Niederlausitz sowie von Ober-

ihre Beziehung zum Späthumanismus in Böhmen und Mähren. Rozpravy Ceskoslovenské akademie vèd - Rada společenských vẻd 98 (1988), Heft 3, S. 16f. - Prokop Lupáć, Ephemeridis historicae liber primus ... Norimbergae 1578, 2. erweiterte Auflage: Rerum Boemicarum Ephemeris sive Kalen. darium historicum ... Pragae 1584 (Rukovéi humanistickèho básnictvi v Čechách a na Moravé S, Praha 1969, S. 221f.); Daniel Adam z Veleslavina, Kalendár historický. Staré Mésto pražské 1578, 2. erweiterte Auflage: Staré Mésto prażské 1590 (Knihopis, Nr. 58 und 59).

4 M. Ziegelbauer, Bibliotheca bohemica (Manuskript). Hieraus schöpfte Pitter, der die Ergānzungen unter dem Titel Commentarixs in Bibliothecam 
und Niederschlesien und des Glatzer Gebietes im Rahmen des. böhmischen Staates lockerte sich bereits im 15. Jahrhundert aus konfessionellen Gründen, und diese Entwicklung wurde gefördert auch durch die enge Verbindung dieser Länder mit. den Universitäten in Krakau, Leipzig, Wittenberg und Frankfurt/Oder, die im 16. und zu Beginn des 17. Jh. anregender als die damals weniger attraktive utraquistische Prager Universität oder die erst nach der Mitte des 16 . Jh. gegründeten Jesuitenuniversitäten in Prag und in Olmütz wirkten.

In Schlesien entstand eine größere Anzahl von Kulturzentren mit dem ökonomisch prosperierenden Breslau an der Spitze. Die Tätigkeit der schlesischen Druckereien des 16. und teilweise auch des 17. Jahrhunderts hing mit der Entfaltung der literarischen Interessen zusammen, die sich auf das städtische Schulwesen stützten. Das BewuBtsein einer kulturellen Eigenständigkeit Schlesiens förderten die dortigen Humanisten durch das Studium der schlesischen Literaturgeschichte, dessen Ergebnisse im 17. und 18. Jahrhundert Nicolaus Henelius, Johannes Henricus Cunradus und Johannes Jakob Fueldener zusammenfaßten. Auch in der Lausitz kam es im 16. Jahrhundert zur Entfaltung des städtischen Schulwesens; es ragte das Gymnasium in Görlitz empor, das auch von vielen

Bohemicam Ziegelbaseri vorbereitete (Manuskript). Diese beiden Werke sind heute verschollen, vgl. J. Kábrt, Bibliografie v dobé temna (Bibliographie in der Zeit der Finsternis), Praha 1964, S. 127 und 142. Man darf auch die bibliographische Tätigkeit von Antonín Koniás nicht außer Acht lassen: Clavis ...Klič, 1729, 1749 und posthum Inder 1770 (Knihopis. Nr. 4286, 4287 und 4298), die allerdings völlig andere Ziele verfolgte. $V_{g l .}$ Bedriazka Wiżálková, Konkordance Koniásových Kliču, Indexu, Jungmanna a Knihopisu (Konkordanz zu Koniábs Schlüsseln, Index, zu Jungmann und Knihopis), in: Prispévky ke Knihopisy 6-10, Praha 1987-88 (Offet der Staatsbibliothek der CSR, Prag).

Notitia illustris Regni Bohemiae scriptorum geographica et chorographica, collecta a Bernardino Erber, S.J. Secerdote. Vindobonae 1760. - Es gab mehrere Versuche, vgl. Josef Hejnic, Schwambergeruv Lexicon eruditorum, Josef Dobrovsky, Adam V. Urban a Bohxmir J. Dlabac (Schwambergers Lexicon eruditorum, Josef Dobrovský, Adam V. Urban und Bohumír J. Dlabac), in: Strahovská knihouna 10 (1975), S. 83-99; Vèra Breñová, Pokusy o soupis ceských tiski ve Strahovaké knihovne (Versuche um Ausarbeitung eines Repertoriums böhmischer Drucke in der Strahover Bibliothek), ebenda, S. 101-111.

Mojmír Švábenský, Cerroniko sbírke ... (Die Sammlung von Cerroni) ... Bend I-III. Brno 1973. Inventére a ketalogy fondr Státniko oblastniko archive $v$ Brne, Nr. 26 (Offet des Staatlichen Kreisarchivs in Brno). 
Studenten aus Böhmen, Mähren und Schlesien aufgesucht wurde.

Systematischere Studien, die das Wirken der Autoren und die typographische Tätigkeit der Druckereien aus der Lausitz zusammenfassen, stammen ebenfalls aus dem 18. Jahrhundert. Das literarische Leben in Böhmen und Mähren stand trotzdem in zahlreichen Beziehungen zur Lausitz, zu Schlesien und zum Glatzer Gebiet, besonders solange diese Länder zum Königreich Böhmen gehörten ${ }^{5}$.

In der Zeit des nationalen Erwachens in Böhmen und Mähren in der ersten Hälfte des 19. Jahrhunderts teilte Josef Jungmann $(\dagger 1847)$ durch sein monumentales Werk Historie literatury české (Geschichte der tschechischen Literatur, 2. Auflage 1849) die ältere Literatur in die tschechische (d.h. in tschechischer Sprache geschriebene) und in die übrige fremdsprachige ein ${ }^{6}$.

Jungmanns Betonung der tschechisch geschriebenen Literatur, die von Beweggründen des nationalen Erwachens gelei-

5 Nicolaus Henelius ab Hennenfeld, Silesiographia renovala ... Wratislaviae 1704; Iohannes Henricus Cunradus, Silesia togata ... Lignicii 1706; Johannes Jakob Fueldener, Bio- et Bibliographie Silesiace d.i. Schlesische Bibliothec- und Br̈cher-Historie. Lauban und Brealau 1729 (2. Auflage 1731); Bronisław Kocowski, Zarys dziejów drukerstwa ne Dolnym Ślgsku. Wroclaw 1948; Wincenty Ogrodziński, Dzieje piśmiennictwa ślgskiego. Do drukz pryygotowali Ludwik Brożek i $Z$ disław Hierowski. Katowice 1965; Encyklopedia wiedzy o ksigice. Wrociaw - Warazawa - Kraków 1971, S. 2510; vgl. Jan Zaremba (und Kollektiv), Bibliografia pismiennictwa polskiego ne Ślgsku XVII. i XVIII. w. Wroclaw - Warszawa - Kraków - Gdańsk 1980. (Bibliografia piśmenictwa polskiego na Ślgsku-Ślgski Korbut 2), S. 13-32.

Petrus Iaenichius, Conspectus Lusatiae literatae ...Wittembergae ...170s d. XVI. Maii IV. dispulationibus repraesentatus, in: Scriptores rerum Lusaticarum II., Lipsiae et Budissae 1719, S. 326-354; Christophorus Staudius, Parnassus Gorliciorum, ebenda, S. 354-367; Christian Knauthe. Annales typographici Lusatiae Superioris, oder Geschichte der OberLausitzischen Buchdruckereyen ... Lauban 1740; Karel Hrdina, Cechove na gymnasir ve Zhorelci (Die Trchechen am Gymnasium von Görlitz). In: Priatelé čsl. starożitnosti svému učiteli. K jedesátinám ...J.V. Simáka (Beilage zu Casopis Společnosti pr̉átel starožitnosti čsl. v Praze, Jg. XXXVIII, Nr. 2-3), Praha 1930, S. 85-98; Antonín Frinta, Lużičti Srbové a jejich pisemnictvi (Die Sorben und ihr Schrifttum). Praha 1955, S. 33f.; Nowy biografiski stownik k slawiznam a kulturje Serbow. Wudawaćelski kolektiw Jan Solta (nawoda), Pėtr Kunze, Franc Š̉n. Budyð̉in 1984. - Siehe auch Anm. 19.

${ }^{6}$ Hrag. von W.W. Tomek, dessen Vorrede in Prag am 20. Oktober 1851 datiert ist; l.J. Hanuz, Dodavky a doplriky k Jungmannové Historii literatury ceské (Ergänzungen und Nachträge zu Jungmanns Geschichte der tschechischen Literatur). Praha 1869. 
tet wurde, hatte außer positiven Seiten (sie weckte das Interesse am nationalen Schrifttum und unterstützte es durch die historische Sicht seiner Entwicklung) auch negative Folgen dadurch wurde das Interesse an den fremdsprachigen Bohemica in den Hintergrund gedrängt, obwohl es um mit den Anfängen der neuzeitlichen europäischen Wissenschaft untrennbar verbundene Werke ging (lateinische Schriften des Dubravius, Gelenius, Hagecius, Iessenius, Zalužanský u.a.) ${ }^{7}$.

Dadurch trat auch das Interesse an der Literatur aus der Lausitz und aus Schlesien in den Hintergrund. Zugleich wurde unorganisch das literarische Schaffen derjenigen Autoren getrennt, die sowohl in Tschechisch als auch in der Fremdsprache publiziert hatten (z.B. Comenius). Weniger Aufmerksamkeit wurde auch den Zusammenhängen zwischen der tschechischen und der fremdsprachigen Literatur geschenkt, und fast völlig beiseite blieb die literarische Tätigkeit der aus deutschsprachigen Teilen Böhmens und Mährens stammenden Autoren.

Die Nachfolger Jungmanns übernahmen diese Einteilung, und so entstanden im Widerspruch zum literarischen Prozeß des größeren Teiles des 16.-18. Jh. zwei Wege beim Studium und der Bearbeitung des damaligen literarischen Schaffens - des tschechischen und des fremdsprachigen - obwohl es um Werke ging, die Bestandteile der gleichen kulturellen Strömung waren und trotz einiger schon durch die sprachliche Seite gegebenen Unterschiede ein einziges organisch verknüpftes Ganzes bildeten. Jungmanns Auffassung setzte Josef Jireček fort durch die Herausgabe (Praha 1875-76) von Rukovět $k$ dèjinám literatury české do konce XVIII. věku ve zpüsobĕ slovnika żivotopisného a knihoslovného (Handbuch zur Geschichte der tschechischen Literatur bis zum Ausgang des XVIII. Jh. in Art eines biographischen und bibliographischen Lexikons), obwohl er sich der Einseitigkeit seines Unterfangens bewuBt war, wie aus seiner Vorrede (Seite VI) hervorgeht:

7 Auf einen engen Zusammenhang des lateinischen Humanismus mit der tschechisch geschriebenen Literatur in Böhmen und Mähren wies schon Josef Hrabák hin (Die Bedeutung des lateinischen Humanismus für die tachechische Literatur und seine Beziehung zur tachechischen Wirklichkeit. In: Renaisance und Humaniomus in Mittel- and Osteuropa. Eine Sammlung von Materialien besorgt von Johannes Irmscher, Band II. Berlia 1962, S. 251-257). 
"Ich verhehle nicht, daß mich mächtig der Gedanke lockte, das Werk auch auf außertschechische Schriftsteller in unseren Ländern auszudehnen, denn dadurch würde sich der Kreis der in unserer literarischen Entwicklung beteiligten Autoren abrunden. Aber der allzugroße Umfang eines solchen Vorhabens lehrte mich bald, daß man sich bescheidener geben muß." Trotz dieser Beschränkung war Jirečeks Lexikon in seiner Zeit von bahnbrechender Bedeutung, weil es das biographische Material für eine "Geschichte des tschechischen Schrifttums" bereitstellte, die Jireček zu schreiben beabsichtigte (nicht realisiert). Unter dem Aspekt einer komplexen retrospektiven tschechischen Bibliographie wurde später Jungmanns und Jirečeks Idee durch Knihopis českých a slovenských tiskí od doby nejstarši ă do konce XVIII. století (Beschreibendes Verzeichnis der tschechischen und slowakischen Drucke von den ältesten Zeiten bis zum Ende des XVIII. Jahrhunderts) erfüllt, wo die kurzen Aufzeichnungen Jungmanns durch eine systematische Erforschung von Büchersammlungen und durch die exakte Beschreibung der festgestellten Druckwerke vollendet wurde, begleitet durch ausgewählte Reproduktionen und vor allem durch die Signaturen der Fonds, in denen die einzelnen Exemplare aufbewahrt werden sowie durch einige $\mathrm{Li}$ teraturhinweise. Knihopis stellt also heute auch einen Generalkatalog der bisher bekannten tschechischsprachigen Drucke dar, wo alle grundlegenden bibliographischen Angaben geboten werden. Methodisch ist er auch für die Drucke des 16.18. Jh. in Anlehnung an den Gesamtkatalog der Wiegendrucke bearbeitet. Die alphabetische Reihe (Teil I - Wiegendrucke), die 1925 von Zdeněk V. Tobolka eröffnet und mit der Beschreibung der Drucke des 16.-18. Jh. fortgesetzt wurde (Teil II; Band 1 erschien 1939), wurde im Jahre 1967 von František Horák beendet. Ergänzungen und Register werden in der Staatsbibliothek der CSR in Prag vorbereitet ${ }^{8}$.

8 Knihopis I ist jetzt ersetzt durch Emma Urbánková, Soupis prvotiski ceského pùvodu (Verzeichnis der Wiegendrucke bōhmischen Ursprungs). Státní knihovna CSR, Praha 1986 (Offet der Staatsbibliothek der CSR); dieselbe, Prameny $k$ prvotiskim ceského pưodu (Quellen zu den Wiegendrucken bōhmischen Ursprungs) I/1-2, II. Státní knihovna CSR, Praha 1983-86 (Offset der Staatsbibliothek der CSR).

Eine erste Orientierung über Knihopis II ermöglicht: Petr Voit, Priopezvky ke Knihopisu (Beiträge zu Knihopis) Bd. 1: Rejotrik extori, prekladatelü 
Wenn fast während des ganzen 19. Jahrhunderts das systematische Studium der fremdsprachigen Bohemica einigermaßen in den Hintergrund gedrängt wurde, bedeutet das nicht, daß es keine Forscher und keine Forscherkollektive gab, die den Boden für eine künftige Synthese vorzubereiten begannen. Zahlreiche Einzeldrucke sind durch die fünfbändige Bibliografie české historie (Bibliographie der böhmischen Geschichte) von Čenëk Zíbrt (Praha 1900-1912) erfaßt, vieles haben die Mitarbeiter von Ottuv slovnik naučný (Ottos Enzyklopädie, Praha 1888 bis 1909) mit Ergänzungen (Praha 1930-43) beschrieben.

Einen zeitlich begrenzten Stoff sollte das von Jirečeks Lexikon hinsichtlich der Methode und auch des Titels inspirierte Werk erfassen, Rukovět k písemnictvi humanistickému, zvlás̆tè básnickému, v Čechách a na Moravẽ ve století XVI. Sestavil Antonin Truhlár (Praha 1908), doplnil a vydal Karel Hrdina (Praha 1918; Handbuch zum humanistischen, besonders poetischen Schrifttum in Böhmen und Mähren im XVI. Jahrhundert. Zusammengestellt von Antonín Truhlár̆, ergänzt und herausgegeben von Karel Hrdina). Dieses Werk blieb ein Torso - es enthält lediglich die Stichwörter A bis Collinus. Angesichts der Tatsache, daß die beiden ersten Bearbeiter ein relativ umfangreiches handschriftliches Material hinterlieBen, das durch Verdienst von Professor Bohumil Ryba auf den Boden der Tschechoslowakischen Akademie der Wissenschaften (weiter nur: CSAV) übergeführt wurde, wobei seine Ergänzung, Bearbeitung und Publizierung als eine bedeutende Aufgabe der

a editori (Register von Autoren, Übersetzern und Editoren), 2: Rejotrik anonymrick zeklavi (Register von anonymen Titeln), s: Rejotrik názoový (Titelregister). Státń knihovna CSR, Praha 1985 (Offset der Staatabibliothek der CSR). Vgl. derselbe, Na okraj dalsiho pokrečováni Knikopisu ceskjich a slovenských tiskü (In Margine der weiteren Fortsetzung von Knihopis ceskýck a slovenských tiskí).In: Cesk d bibliografie 22 (1986), S. 102-117.

Eine Bibliographie tschechischer Bänkellieder, die in Krihopis nur zeitlich begrenzt evidiert sind ( und in den Ergãnzungen überhaupt nicht mehr erscheinen werden), wird von der Bibliothek des Nationalmuseums Prag erarbeitet; zu dieser Problematik vgl. Karel Bezdék - Eva Ryłavá, Ceské kramátské pisniové tisky, jejich bibliograficke zpracaváni a rkäzka biblio. grafie 19. stoleti (Tschechische Bänkelliederdrucke, ihre bibliographische Bear. beitung und eine Probe der Bibliographie des 19. Jh.), in: Sbornik Národniko muzea v Praze. Reihe $C$ - Literárni historie $X X V I I I$ (1983), Nr. 4, S. 173201.

Offizielle Drucke amtlichen Charakters wurden in den Knihopis nur ausnahmsweise aufgenommen. Siehe Knihopis II 1, Stichwort: "Artikulové". 
Forschung formuliert wurde, wurden die Fortsetzer von Truhláŕ und Hrdina, Josef Hejnic und Jan Martinek, damit beauftragt, vor allem die lateinische Poesie zu studieren ${ }^{9}$.

Diese Auffassung ist einmal in der Vorrede begründet, zum anderen in dem ein wenig veränderten Titel angedeutet: Rukovět humanistického básnictví v Čechách a na Moravè od konce 15. do začdtku 17. století (Handbuch der humanistischen Poesie in Böhmen und Mähren vom Ausgang des 15. Jh. bis zum Beginn des 17. Jh. Band 1-5, Praha 1966-1982). Die Zeitgrenze reicht vom Beginn der Regierung Wladislaw Jagiellos (1471) bis zur Schlacht am WeiBen Berge (1620); aus der darauffolgenden Zeit werden nur diejenigen Autoren evidiert, die bereits vor 1620 literarisch tätig waren. Im Laufe der Studien stellte sich heraus, daß die humanistische Poesie in Böhmen und Mähren in solchem Maße mit der Tätigkeit der Partikularschulen und der Prager utraquistischen Universität zusammenhing, der Institutionen, die in den Händen des städtischen Standes lagen, daß man sie als eine der grundlegenden literarischen Ausdrucksarten der böhmischen ständischen, in erster Linie allerdings städtischen Gesellschaft, auffassen kann. Die fünf Bände von Rukovět, zu denen wohl in absehbarer Zeit ein sechster Band mit Ergänzungen und ein siebenter Registerband hinzukommen wird, bringen auch eine Reihe von Belegen über die enge literarische Verbindung zwischen tschechischen, mährischen, lausitzischen und schlesischen Humanisten, die eine vereinheitlichende Bewegungskraft des kulturellen Lebens in den böhmischen Kronländern waren und auch gemeinsam ihre Entwicklung im Einklang mit dem kulturellen Geschehen in den übrigen mitteleuropäischen und westeuropäischen Regionen sicherten.

Das systematische Studium der humanistischen Prosa, die verlegerisch, inhaltlich und formal mit einem breiteren europäischen Hinterland zusammenhängt, schlossen die beiden

9 Zum Verhältnis zwischen Truhláis und Truhlái-Hrdinas Rukovẽi vgl. Rukovēi humanistického básnictvi v Cechäch a na Moravé 1, Praha 1966, S. 10 (mit Verweisen auf weitere Literatur). - Im folgenden werden nur diejenigen Aspekte erfabt, die für das Studium der humanistischen Prosa von Bedeutung sein können. Eine ausführliche Information über die Methode, mit der Rukovéi bearbeitet wurde, ist in der Vorrede zum 1. Band angeführt. 
Autoren von Rukovět humanistického básnictví vor mehr als 30 Jahren absichtlich aus ihren Forschungen aus und überließen es einer späteren Zeit ${ }^{10}$.

Wie bei Truhlár und Hrdina wurde auch in der neubearbeiteten Fassung von Rukovět das Material in Form eines biobibliographischen Lexikons angeordnet, das besonderen Nachdruck legte auf die literarische und inhaltliche Seite der einzelnen Schriften, auf lokale Beziehungen, besonders aber auf die Biographien der Humanisten, die auf der Basis von ursprünglichen Quellen und der zugänglichen Literatur erarbeitet wurden" ${ }^{11}$. Es kommt nur ein einziges Sachstichwort, "Carmina gratulatoria", vor, wo kollektive Glückwunschsammelschriften anläßlich der gemeinsamen Universitätspromotionen einiger Persönlichkeiten zusammengefaßt werden. Ähnlich wie Knihopis, wenn auch nicht in solcher Breite, zitiert Rukovět die festgestellten Signaturen der Drucke, und zwar auch solche, die aus der Fachliteratur und aus Bibliographien übernommen wurden.

Die vorbereiteten Ergänzungen werden größtenteils Unikate enthalten. Ein spezifisches Merkmal von Rukovët, das in der Evidenz der inhaltlichen Seite der beschriebenen literarischen Einheiten über den Knihopis hinausgeht, ist auch die Eingliederung von handschriftlich erhaltenen Werken einzelner Autoren sowie die systematische Registrierung aller ihrer festgestellten literarischen Äußerungen (d.h. auch deutscher, französischer u. a.; die tschechischen werden durch Hinweis auf Knihopis evidiert), und 2 war auch kleiner Werke, z.B. der in Gelegenheitsdrucken von Sammelschriftcharakter erschienenen Gedichte. Es werden auch die meisten Dedikationen an Autoren und humanistische Mäzene registriert

10 Rrkoveí hrmanistického básnictvi 1, Praha 1966, S. 11: "In Zukunft ist übrigens an die Erarbeitung eines Handbuchs der humanistischen Prosa gedacht, das ein gewisses Gegenstück zu Rukovët wäre, allerdings mit dem Vorbehalt, daB angesichts der Andersartigkeit des Materials die Prinzipien der Bearbeitung ein wenig anders wären und daß der Hauptnachdruck sich auf die Erfassung dessen konzentrieren würde, was an der humanistischen Prosa wesentlich ist, nämlich auf den wissenschaftlichen Beitrag des Schaffens einzelner Autoren."

11 Dazu vgl. Jan Martínek, $O$ pramenech zivotopisnych idajü o Eeskjich hrmenistech (Û̉ber die Quellen von biographischen Angaben über böhmische Humanisten). In: Listy filologické 9s (1970), S. 196-202 (mit Hinweisen auf weitere Literatur). 
und systematisch wird auf andere Formen von Namen der aufgenommenen Autoren oder Empfänger von Gelegenheitsdrucken hingewiesen. Solche Hinweise erschienen zwar auch schon in Truhlárs und Hrdinas Rukovět, allerdings unsystematisch. Im Vergleich zu Knihopis bringt Rukovët keine typologischen Analysen von Drucken und beschreibt nur ganz ausnahmsweise und sehr kurz die graphische Gestaltung, verzeichnet Illustrationen, Buchdruckersignets usw. Diese Angaben wird das fremdsprachige Gegenstück von Knihopis, d.h. das Werk Bibliografie cizojazyčných bohemikálních tiskü $z$ let 15011800 (Bibliographie der fremdsprachigen bohemikalen Drucke aus den Jahren 1501-1800), auf dessen Erscheinen die Fachwelt noch wartet, bringen ${ }^{12}$. Zu dessen Förderung wurde im Jahre 1967 eine spezielle Forschungsstelle in der Hauptbibliothek der Tschechoslowakischen Akademie der Wissenschaften gebildet.

Mit der Erfassung fremdsprachiger Bohemica wurde zwar schon in der Hauptbibliothek der ČSAV in der Mitte der 50er Jahre begonnen, allerdings nahm sich dieser Aufgabe jene Forschergruppe an, in der damals unter Leitung von František Horák noch die Arbeiten am Knihopis beendet wurden ${ }^{13}$.

Die bibliographische Beschreibung der fremdsprachigen

12 Als Zdenèk V. Tobolka zu Beginn der 20er Jahre mit der Initiative auftrat, zunächst die gedruckte tschechische Produktion bibliographisch zu bearbeiten, bestätigte er damit definitiv die erwähnte $Z$ weigleisigkeit der nationalen retrospektiven Bibliographie, ohne daB allerdings parallele Forschungsgruppen für die gleichzeitige Bearbeitung der tschechischen und fremdsprachigen Drucke geschaffen worden wären. Im Gegenteil - die nationale Retrospektive blieb jahrzehntelang auf die Bewaltigung der tschechisch gedruckten Produktion ausgerichtet, so daB die fremdsprachigen Bohemica perspektivisch erst hinter dem Krihopis eingereiht wurden und von allen zeitlichen Verzögerungen beim Erscheinen seiner Bände betroffen wurden.

13 Bohumil Ryba, $K$ chystanému soupisu cizojazycinych bohemik (Zum vorbereiteten Verzeichnis der fremdsprachigen Bohemica), in: Védecké informace CSAV, Suplement 2. Praha Zakladni knihovna - Ústiedi vèdeckých informaci CSAV 1968, S. 1-2 (Offret); Mirjam Bohatcová, Verzeichnisse gedruckter Bohemica von 1501 bis 1800, in: Gutenberg-Jahrbuch 1968, S. 136-138; Bohuslava Brtová, Soupis cizojazyçnych bohemik \& let 15011800 (Verzeichnis der fremdsprachigen Bohemica aus den Jahren 1501-1800), in: Vedecké informace CSAV, Suplement s. Praha Základni knihovna Ústredí vedeckých informací CSAV 1973, S. 54-61 (Offset); Anezkka Badurová, Bibliografie eizojazyenych bohemikálnich tiski z let 1501-1800 v ZK-ÚVI CSAV (Bibliographie der fremdsprachigen bohemikalen Drucke aus den Jahren 1501-1800 in der Hauptbibliothek - Wissenschaftliches Informationszentrum der CSAV), in: III. nórodni konference o bibliografii v CSR. Sbornik materiálì. Praha, Státní knihovna CSR 1987. Bd. 2, S. 332-35 (Offret). 
Bohemica basiert, ebenso wie bei Knihopis, auf dem direktem Kontakt mit dem Material (Beschreibung de visu) und wird sio detailliert ausgearbeitet, daß sie nicht nur ausreichend über dem Inhalt des Werkes informiert, sondern auch zur Differenzierung verschiedener Ausgaben dient: Die Titelseiten werden im vollem Wortlaut unter Beibehaltung der verwendeten Orthographie abgeschrieben, es werden erfaßt Vorreden, Dedikationen, Approbationen, Zensuren, Privilegien, Imprimatur, Titel einzelner Textteile, Register, Literaturverzeichnisse, Errata, Mitteilungen an die Buchbinder sowie die graphische Gestaltung des Druckes (Technik, Ausmaße und Themen von Illustrationen oder anderer bedeutender Verzierungen, Drucker- und Verlegersignets). Die Bilanz der bisher geleisteten Forschung ist gut und vielversprechend - die mehr als 22000 bibliographisch bearbeiteten Einheiten geben eine Vorstellung vom Reichtum böhmischer und mährischer Büchersammlungen, wenn wir bedenken, daß es sich bisher vorwiegend um Drucke aus den Fonds der Prager Bibliotheken handelt.

Das Stichwörterverzeichnis der vorbereiteten Bibliographie, in dem neben Aufzeichnungen bereits bibliographisch beschriebener Drucke auch Desiderata erscheinen, d.h. auf der Basis sekundärer Quellen erstellte Eintragungen, enthält heute an die 40000 Titel, wobei auf das 16. und 17. Jh. etwa die gleiche Anzahl entfällt, die Knihopis für alle drei Jahrhunderte verzeichnet (etwa 17000 ). An dieser Zahl beteiligen sich allerdings in beträchtlichem Maße auch die sog. inhaltlichen Bohemica, mit deren Publikation vorläufig nicht gerechnet wird ${ }^{14}$.

Die Quantität des für die Bibliographie der fremdsprachigen Bohemica zusammengetragenen Materials, die bereits darauf verwendete Zeit sowie die nüchterne Beurteilung der objektiven Bedingungen für eine bibliographische Forschung außerhalb Prags (nicht katalogisierte Fonds, Mangel an Mitarbeitern u. dgl.) veranlaßten $z u$ Überlegungen über eine nach und nach zu erfolgende Publizierung der geplanten Bibliographie nach einzelnen Gesichtspunkten. An die erste Stelle rückten die fremdsprachigen Druckerbohemica des 16. und 17. Jh.,

14 Es handelt sich 2.B. um Werke von gesamteuropäischer Ausrichtung, in denen die bohemikale Problematik nur in einigen Passagen auftritt; diese Werke ausländischer Autoren wurden alle auberhalb des Territoriums von Böhmen und Māhren herausgegeben. 
die ein Ensemble von vorläufig etwa 6000 Aufzeichnungen darstellen, auf dessen Publikation sich nun die Anstrengungen der bibliographischen Forschungsstelle in der Hauptbibliothek - wissenschaftliches Informationszentrum der CSAV konzentrieren. Schlesien und die Lausitz werden weder in Knihopis, noch in Rukovět humanistického básnictvínoch in der geplanten Bibliographie der fremdsprachigen Bohemica erfaßt. Man wird sie getrennt behandeln müssen.

Auch die literarhistorische Forschung könnte durch die anwachsende Anzahl der bibliographischen und buchwissenschaftlichen Untersuchungen neu angeregt werden: Die bisherige akademische Dëjiny české literatury (Geschichte der tschechischen Literatur, Band 1. Praha 1959) behandeln die literarische Entwicklung des 16.-18. Jh. nur in sprachlich und gattungsmäBig begrenztem Umfang, wobei vor allem Werke der Fachliteratur vernachlässigt werden, die in manchen Zeitabschnitten Schlüsselbedeutung hatten. Eine systematische Bearbeitung wird auch das von Rukovět humanistického básnictví präsentierte Material erfordern: Die Pflege der Poesie setzte gründliche Sprachkenntnisse voraus, die sich auf das Studium der Grammatik stützten, und diese bildete die Grundlage der für den Humanismus so charakteristischen philologischen Orientierung.

Ein Teil der bohemikalen fremdsprachigen Prosa und Poesie des 16.-18. Jahrhunderts ist deutsch; sie sollte Gegenstand der besonderen Aufmerksamkeit von Germanisten sein. Die bisher stets zitierte Bearbeitung von Rudolf Wolkan, Böhmens Anteil an der deutschen Literatur im XVI. Jahrhundert (Prag 1890) ist unvollständig und schon allein vom zeitlichen Standpunkt aus beschränkt. Das gleiche kann auch von einigen weiteren Spezialbibliographien gesagt werden ${ }^{15}$.

15 Paul O. Kristeller, Remaissance Thought. The Classic Scholastic and Hxmanist Strains. New York 1961, S. 110.

Über die Notwendigkeit, auch deutschsprachige bohemikale Literatur zu studieren, vgl. Ferdinand Seibt, Bohemica. Probleme and Literatur seit 1945. Historische Zeitschrift - Sonderheft 4, München 1970, S. 139. Eine erfolgreiche Untersuchung der deutschen Barockliteratur in tschechoslowakischen Bibliotheken unternahm Leonard Forster, Iter Bohemicum. A report on German barogue literature in Czechoslovak libraries. Rodopi N.V.: Amsterdam 1980 (Beihefte zum Daphnis 4). 


\section{Ziele der weiteren Forschung}

Unsere historische Übersicht der bisherigen Arbeiten deute!t an, daB sich das Studium des handschriftlichen und gedrucktem Materials des 16.-18. Jahrhunderts in Böhmen und Mährem auf zwei Ebenen bewegte, und zwar auf der Ebene der bibliographischen Grundlagenforschung (das chronologisch und sachlich angeordnete Werk von Jungmann; der alphabetisch nach Autoren geordnete Knihopis und die Bibliographie der fremdsprachigen bohemikalen Drucke) und auf der Ebene einer tieferen und breiteren Forschung bio-bibliographischer, philologischer und literarhistorischer Natur (Jireček; Rukove $\check{t}$ humanistického básnictví). Das bohemikale literarische Material aus dem 16.-18. Jh. ist allerdings so reich und vielgestaltig, daß man unter den heutigen Bedingungen kaum an seine einmalige Bearbeitung denken kann, die sowohl rein bibliographische als auch philologische, kunsthistorische und literaturhistorische Aspekte über den ganzen Zeitraum hin umfassen würde, und zwar umso mehr, als es in jener Zeit in Böhmen und Mähren zu gesellschaftlichen Veränderungen kam, die nicht ohne Widerhall in der literarischen Praxis und Buchproduktion blieben.

In Betracht gezogen werden muß auch die heute ständig voranschreitende Spezialisierung der einzelnen Wissenschaftsdisziplinen (z.B. Astronomie, Mathematik, Medizin) und die dadurch steigenden Anforderungen an die Untersuchung der einzelnen Probleme nicht nur unter rein bibliographischem Aspekt (Frage der chronologischen Bestimmung undatierter Drucke; Frage der typographischen Bestimmung der ohne Impressum erschienenen Paläotype; Frage der Herkunft und Migration von Dekor- und Illustrationselementen, z.B. von Holzschnitten, Stichen u. dgl.), sondern auch unter literaturhistorischem Aspekt (Bestimmmung der Autorschaft anonymer Schriften, des sprachlichen Stils, der literarischen Orientierung und der späteren Wirkung des Werkes). Ähnlich wie Jireček und die Herausgeber des Knihopis die Bohemica des 16.-18. Jh. nur um den Preis eines Verzichts auf das Verzeichnen der zeitgenössischen fremdsprachigen Literatur und der Drucke amtlicher Natur zu bewältigen imstande waren, zeigte sich eine analoge Tendenz zur Re- 
duktion auch beim Studium und Erfassen der humanistischen Literatur. Während Antonín Truhlár und Karel Hrdina ihr Werk als Handbuch zum humanistischen, besonders poetischen Schrifttum bezeichneten, beschränkten sich ihre Fortsetzer, wic oben gezeigt, bewußt auf die humanistische Poesie. Auch bei der Zusammenstellung der Bibliographie der fremdsprachigen bohemikalen Drucke aus den Jahren 1501-1800 wird nun an die Realisierung des Zielvorhabens in Form einer nach und nach erfolgenden Publizierung gedacht, um den ständig steigenden Anforderungen an die bibliographischen Unterlagen bereit $\mathrm{zu}$ entsprechen.

Das zugängliche gesamteuropäische Material muß in einige Zeitabschnitte eingeteilt werden, die freilich angesichts der unterschiedlichen Entwicklungstendenzen in den einzelnen Ländern differieren ${ }^{16}$. Bei der Periodisierung der böhmischen Geschichte wird meist über die Grenzen setzende Bedeutung des Jahres 1620 gesprochen.

Die Kompliziertheit der ganzen Problematik in den böhmischen Kronländern zeigt z.B. die Entwicklung der lateinischen Prosa. In Böhmen verzeichnete sie einen beträchtlichen Aufschwung bereits an der Wende des 16. zum 17. Jahrhundert, wo die Bedeutung Prags als Zentrum des wissenschaftlichen Lebens in der Zeit Rudolfs II. anstieg und wo das Lateinische, besonders in der Fachliteratur, seine führende Position beibehielt. Nach der Stagnation während des Dreißigjährigen Krieges blieben die Beziehungen der lateinischen Prosa zum zeitgenössischen europäischen Kontext nur auf einige Bereiche beschränkt, besonders auf dem Gebiet der Theologie,

16 In der bibliographischen Praxis der deutschsprachigen Länder setzt sich eine scheinbar strikt mechanische Gliederung durch: Die Münchner Bayerische Staatsbibliothek ist das Zentrum für das Studium der Drucke des 16. Jh., in der Wolfenbütteler Herzog August Bibliothek konzentriert sich die Forschung auf die Paläotype des 17. Jh., während das Studium der im 18. Jh. erschienenen Literatur sein Zentrum in der Universitätsbibliothek in Göttingen hat - in der DDR wurde ein analoges Zentrum für das Studium der Literatur des 18. Jh. in Weimar errichtet. Diese Gliederung wird durch den Umstand unterstützt, daB die Literatur der Barockzeit gewöhnlich in das 17. Jh. gelegt wird, so daB sich die mechanische Einteilung in diesem Falle im wesentlichen mit der literaturhistorischen deckt. Dem ist allerdings nicht in jedem Land so-2.B. die Franzosen suchen den Anfang des literarischen Barock um das Jahr 1585, vgl. Roméo Arbour, L'ère baroque en France I-IV. Genève 1977-1985, besonders L, S. VIII-IX. 
Philosophie und Geschichte. Erst nach der Aufhebung des Jesuitenordens im Jahre 1773, der in Böhmen und Mähren die lateinischen Mittel- und Hochschulen beherrscht hatte, umd nach der Durchsetzung der Ideen der Aufklärung (Josefinismus) begannen sich in den böhmischen Ländern auch erste neuzejtliche wissenschaftliche Gesellschaften mit vorwiegend naturwissenschaftlicher Ausrichtung zu Wort zu melden ${ }^{17}$.

Die Forderung nach einem systematischen Studium der fremdsprachigen, besonders der lateinischen Prosa in den böhmischen Kronländern ist nicht neu. Auf ihre Bedeutung machten schon früher einige Forscher aufmerksam (z.B. Jaroslav Ludvíkovský, Antonín Škarka), die zugleich anführten, daf das Jahr 1620 in der lateinischen Prosa keine so ausgesprochene Grenze bildet wie in der Poesie. Daraus ergab sich logisch das Bedürfnis (auch durch breitere europäische Beziehungen begründet), die lateinische Prosa mindestens bis zum Ende des 17. Jh. zu verfolgen, eventuell bis zum Ende des 18. Jahrhunderts ${ }^{18}$.

Eine gewichtige, bisher ungelöste Aufgabe stellt in diesem Zusammenhang das Studium der fremdsprachigen Literatur dar, deren Entstehung und Veröffentlichung mit denjenigen Territorialeinheiten verbunden ist, die bis 1635 (Ober- und Niederlausitz) bzw. bis fast zur Mitte des 18. Jh. (1742 Schlesien mit dem Glatzer Gebiet) einen Bestandteil des Königreichs Böhmen bildeten. Die Bearbeitung der Bibliographien durch lausitzische, deutsche, polnische und tschechische Forscher würde die Möglichkeit eines kollektiven Vorgehens beim Studium dieses bedeutsamen Kapitels nicht ausschließen, das für die ältere böhmische Geschichte und Literaturgeschichte in mancher Hinsicht von grundlegender Bedeutung wäre, weil seine systematische Untersuchung ermöglichen würde, $\mathrm{zu}$ ver-

17 Ferdinand Seibt, op. cit., S. 140; Jaroslav Purs - Miroslav Kropilak (red.), Prehled dejin Ceskoslovenske (Geschichte der Tschechoslowakei in Überblick) $1 / 2$. Praha 1982, S. 446.

$18 \mathrm{~J}$. Ludvikovský, Antike a ceská vzdélanost od husitstvi do Bié hory. Problémy a úkoly (Die Antike und die tschechische Bildung von der Hussitenzeit bis zur Schlacht am Weißen Berge. Probleme und Aufgaben), in Ladislav Varcl (red.), Humanistická konference 1966, hrsg. vom Kabinst pro studia recká, rímská a latinská CSAV v Praze (Offset), S. 29; A. Skarka, Poznámky k "déjinám" ceského hrmenismu (Bemerkungen zur "Geschichte" des böhmischen Humanismus), ebenda, S. $39 \mathrm{ff}$. 
läßlicheren Schlußfolgerungen über die Entwicklungstendenzen sowohl der lateinischen Poesie und Prosa als auch der jeweiligen Nationalliteraturen im gegebenen Gesamtkontext zu gelangen $^{19}$.

Dies sind allerdings heute noch ziemlich entfernte Ziele. Die nächsten Schritte werden wahrscheinlich Ergänzungen zu Knihopis und zu Rukovět humanistického básnictví betreffen, die bald durch die Bibliographie der fremdsprachigen Bohemica befolgt werden könnten. Auch eine systematische Analyse der zeitgenössischen lateinischen Prosa wäre sehr wünschenswert. In methodischer Hinsicht sollte sich dieses Studium der lateinischen Prosa nach analogen Grundsätzen wie in Rukovĕt humanistického básnictví richten, woran man durch Hinweise (Biographien) und eventuell auch durch Nachträge anknüpfen könnte. Die enge Zusammenarbeit mit Spezialisten der einzelnen Wissenschaftsdisziplinen ist eine Voraussetzung für den Erfolg. Die Vorgangsweise der Arbeit könnte beschleunigt und in methodischer Hinsicht vervollständigt werden durch die $\mathrm{Zu}$ sammenarbeit mit der Bibliographie der fremdsprachigen bohemikalen Drucke, mit der Staatsbibliothek der ĆSR, mit dem Archiv der Karlsuniversität, eventuell auch mit anderen Institutionen. Ähnlich wie in Rukovět humanistického básnictvísollten auch Handschriften zum Studienobjekt werden, besonders wenn sie Werke von wissenschaftlich oder sonst literarisch tätigen Autoren waren und teilweise nur wegen der Ungunst der Zeit unveröffentlicht blieben. Als erster konkreter Schritt zum systematischen Studium der lateinischen Prosa des 16. und 17.

19 Vgl. Mirjam Bohatcová, Humanistické jednolisty z Luzice (Humanistische Flugblätter aus der Lausitz). Ostrava 1957, S. 5 f.; dieselbe, Einige nähere Angaben über die Tätigkeit des Druckers Johann Jäger (Zittau 1610-1619). Gutenberg-Jahrbuch 1980, S. 155 - 173; Václav Pumprla, Soupis starjich tisku ve fondech Státni vėdecké knihouny v Olomorci (Verzeichnis der alten Drucke in den Fonds der Staatlichen Wissenschaftlichen Bibliothek in Olomouc) $I I / 2$ : Tisky z Budyina, Cvikova, Drádan, Zhorelce a Zitavy 1501-1800 (Drucke aus Bautzen, Zwickau, Dresden, Gōrlitz und Zittau 1501-1800), Olomouc 1981; derselbe, Vratislavské tisky z let 1501-1800 (Breslauer Drucke aus den Jahren 1501-1800), Olomouc 1982. In beiden Fälen handelt es sich um OffsetPublikationen aus der Reihe: Publikace Státni védecké knikovny v Olomouci. - Über die schlesischen Drucke in den mährischen bistorischen Bibliotheken schrieb Ludmila Čuprová, Silesiaka v moravských knikovnách v 17. a 18. otoletí (Silesiaca in mährischen Bibliotheken im 17. und 18. Jh.), in: Slezský sbornik - Acta Silesiaca 64 (1966), S. 380-389 und 543-552. 
Jh. sollten seine Grundkonzeption und seine Ziele formuliertt werden.

Auf dieser Basis sollte dann als zweites das Stichwörterverzeichnis ausgearbeitet werden und durch ausgewählte Sondem in Materialien unterschiedlichen Typus auch die Arbeitsmethoden erwogen werden. Diese Sonden sollten in Form von Probestichwörtern oder Teilen davon der fachlichen Öffentlichkeit zur Beurteilung vorgelegt werden.

Angesichts der bisherigen Erfahrungen kann angenommem werden, daß die Materialbasis der bohemikalen lateinischen Prosa in qualitativer und quantitativer Hinsicht einmal in de:r Zeit Rudolfs II. kulminieren wird, zum anderen in der Zeit, in die die literarische Tätigkeit von Jan Amos Komenský ( $†$ 1670) und Bohuslav Balbín ( $\dagger$ 1688) fällt ${ }^{20}$.

Die Einordnung dieser beiden Höhepunkte in zwei Arbeitsetappen (vor und nach 1620) scheint zweckmäßig, und zwar nicht nur etwa aus inhaltlichen und formalen Gründen, sondern auch deshalb, weil in der zweiten Phase (lateinische Literatur des Zeitalters nach der Schlacht am Weißen Berge) gleichzeitig sowohl lateinische Prosa als auch Poesie bearbeitet werden könnte. Es wird nötig sein, in analoger Weise auch die übrige fremdsprachige Literatur aus den böhmischen Ländern, der Lausitz und aus Schlesien zu erfassen und zu untersuchen. Eine detaillierte Erfassung, Analyse und Einschätzung des Materials würde verläßliche Voraussetzungen für ein Studium der Anfänge der modernen Gesellschaft in Böhmen und Mähren liefern. In der Vergangenheit kam es allerdings überall und allgemein (wenn auch aus unterschiedlichen Gründen und in

20 Emma Urbánková, Soxpis del J. A. Komenskêho v Eeskoslovenských knikovndeh, archivech a museích (Verzeichnis der Werke von J. A. Komenský in tachechoslowakischen Bibliotheken, Archiven und Museen), Praha 1959; Bohuslava Brtová und Stanislava Vidmanová, Seznam dell J. A. Komenakého uchovanjich pouze v zahranict. Tisky do r. 1670 (Verzeichnis der ausschlieBlich im Ausland aufbewahrten Werke von J. A. Komenský. Drucke bis zum Jahre 1670), in: Studie Comeniana et historica. Musaexm Comenii Hanno Brodense VIII (1978), Nr. 18, \$. 123-228. - Alena Richterová,

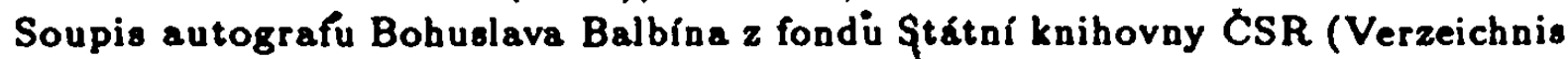
der Autographe von Bohuslav Balbín aus'den Fonds der Staatsbibliothek der CSR), Praha 1988 (Offret der Staatsbibliothek der CSR, Prag); Anezka Badurová (red.), Bibliografie spisu Bohuslava Balbina vytizténych do roku 1800 (Bibliographie der bis 1800 gedruckten Schriften Bohuslav Balbins), Praha 1989 (Hauptbibliothek - Wissenschaftliches Informationszentrum der CSAV. Prag), im Druck (Offset). 
verschiedenem Ausmaß) zu Verlusten. Es handelt sich um ein Memento, das zu kritischer Zurückhaltung auch beim Studium von anscheinend einfachen und problemlosen Fragen auffordert.

Die Realisierung der oben angeführten Aufgaben bei sich nicht überschneidender Zusammenarbeit von Institutionen und einzelnen Forschern stellt die Gesellschaftswissenschaften vor eine Perspektivaufgabe - die Bearbeitung und Bewertung der literarischen und verlegerischen Tätigkeit in den historischen Grenzen des böhmischen Staates in einem einheitlichen Ganzen. Es geht um eine Aufgabe, die nicht nur die Bibliographie, Literatur und Buchwissenschaft berührt, sondern, wie bereits angeführt, viele weitere Wissenschaftszweige. An dem allgemeinen Nutzen dieser Forschung kann kein Zweifel bestehen. Durch das Registrieren der Ergebnisse dieser ungemein schwierigen und verantwortungsvollen, aber auch außerordentlich wertvollen Untersuchungen wäre es schließlich möglich, den Aufstieg und Niedergang einzelner Wissenschaftszweige, der gesellschaftlichen und Sprachgruppen, der literarischen Gattungen, des unternehmerischen Neuertums, der Erfolge und MiBerfolge von Verlegern, Autoren und Künstlern fast exakt zu belegen, regionale Bestrebungen zu untersuchen, ihre Äußerungen und ihren Nährboden, Protagonisten kennenzulernen und Epigonen auszusondern, sich der funktionalen und destruktiven Elemente bewußt zu werden und schließlich nach breiteren und allgemeineren Zusammenhängen all dieser Erscheinungen Ausschau zu halten. 


\section{Bibliographische Beilage}

\section{Zusammengestellt von Anežka Badurová}

Das Studium des literarischen Schaffens vergangener Jahrhunderte ist ohne die Bearbeitung der primären Quellen, d.h. der historischen Bücherfonds, nicht denkbar. In fast allen Ländern, die eine synthetische Sicht der Vergangenheit der eigenen Buchkultur anstreben, treten zwei Arten der Erfassung des nationalen Bucherbes in den Vordergrund: 1. die Erstellung von Gesamtkatalogen und retrospektiven $\mathrm{Bi}$ bliographien, 2. die detaillierte Katalogisierung und Auswertung der einzelnen Bücherfonds. Das Übergewicht der einen oder der anderen Art wechselt in Abhängigkeit von der konkreten Forschungsbedingungen, aber im wesentlichen hängen beide Arten eng zusammen und bedingen in wechselseitigem Verhältnis die erreichten Ergebnisse. Um unsere Abhandlung unter diesem Aspekt nicht durch einseitige Ausrichtung auf Arbeiten mit komplexem Charakter einzuschränken, fügen wir in Form einer bibliographischen Beilage eine Übersicht von bisher publizierten Katalogen und thematischen Teilverzeichnissen von alten Drucken aus den einzelnen Bibliotheken Böhmens und Mährens bei. Es handelt sich nur um solche Publikationen, die, vollständig oder überwiegend, katalogisierte Eintragungen oder wenigstens kurze Verzeichnisse von alten Drucken darstellen, die in der betreffenden Institution aufbewahrt und verwaltet werden.

Es wurden hier also nicht solche Studien aufgenommen, die ein heute bereits verstreutes oder verlorenes Bibliotheksensemble rekonstruieren. Ebenfalls wurden nicht diejenigen Verzeichnisse erfaßst, die auf der Basis einer begrenzten thematischen Untersuchung der einzelnen Bibliotheken entstanden sind. Das gleiche betrifft diejenigen Studien, die nur die Geschichte und das Profil der historischen Fonds darstellen. Auch zusammenfassende Abhandlungen über die Problematik solcher Untersuchungen fehlen hier. Mit den historischen Bibliotheken Böhmens und Mährens befaßt sich heute eine relativ große Anzahl von Studien, die eine selbständige Bibliographie verdienen würden. Solche Untersuchungen werden auszugs- 
weise bei Miroslava Hejnová in Bibliografie soupisu historických fondì na územi Čech a Moravy z let 1800 - 1980 /Bibliographie von Verzeichnissen der historischen Fonds auf dem Territorium Böhmens und Mährens aus den Jahren 1800 $1980 /$ erfaßt $^{21}$. Der Zweck unserer Beilage soll lediglich eine Information darüber sein, welche Bücherfonds auch ein ausländischer Forscher mit Hilfe von gedruckten Katalogen und Verzeichnissen einsehen $\mathrm{kann}^{22}$. Aus diesem Grunde werden, bis auf kleine Ausnahmen, in dieser Beilage die erst nach 1950 entstandenen Abhandlungen zitiert, als in Böhmen und Mähren viele historische Bibliotheken nach und nach eine neue und definitive Lagerung unter staatlicher Verwaltung fanden.

Man muß dabei bedenken, daß sich besonders in den ehemaligen Schloß- und Klosterbibliotheken Böhmens und Mährens ein reichhaltiges Material befindet, das - wegen seines Umfangs - noch nicht auf genügende Weise vollständig bearbeitet ist. Die folgenden Untersuchungen geben in chronologischer Reihenfolge - Informationen über die Betreuung, über die Organisation der Verwaltung und über die Problematik der Bearbeitung dieser Fonds in der Nachkriegszeit:

Bohumír Lifka, Knihovny státních hradủ a zámkü /Die Bibliotheken der staatlichen Burgen und Schlösser/. Praha, Státní tělovýchovné nakladatelství 1954. $30 \mathrm{~S}$.

${ }^{21}$ Praha, Státni knihovna CSR 1985. 34, (5) S. (230 Eintragungen, Offretdruck).

${ }^{22}$ Den Leser, der sich für böhmische Wiegendrucke interessiert, verweisen wir auf die in der Anmerkung 8 zitierte Publikationen von Emma Urbánková sowie auf drei Beiträge von Mirjam Bohatcová: auf ihren Artikel Die Anfänge des bohmischen Buchdrucks im Lichle nexerer Literalur (GutenbergJahrbuch 1979, S. 157-167), auf die die Tschechoslowakei betreffenden Eintragungen im Werk Der Buchdruck im 15. Jahrhundert, Teil 1. Bibliographie (herausgegeben von Severin Corsten und Reimar Walter Fuchs unter Mitarbeit von Kurt-Hans Staub, Stuttgart 1988) und auf ihre im Grtenberg-Jahrbuch 1987, S. 265-278, publizierte Untersuchung, die unsere Abhandlung angeregt hat /Der gegenwärtige Bearbeitungsatand der Druckproduktion vom 15. bis zum 18. Jakrkundert in den böhmischen Ländern/. 
Bohumír Lifka, Knihovny státních hradů a zámkủ v českñ'ch zemích v období 1945 - 1955 /Die Bibliotheken dier staatlichen Burgen und Schlösser in den böhmiscthen Ländern im Zeitraum von 1945 - 1955/. In: Knihovna, Časopis Svazu českých knihovníku 8, 1955, S. 159-162.

Bohumír Liffa, Zámecké, hradní a palácové historické knihow:ny v českých zemích ve sfére Národního mussea /Historische Burg-, SchloB- und Palastbibliothelken in den böhmischen Ländern in der Verwaltung dles Nationalmuseums/. In: Časopis Národního musiea - Oddíl věd společenských 127, 1958, S. 169-174..

Anna Vavroušková, Farní knihovny v severních Čech.ách /Pfarrbibliotheken in Nordböhmen/. In: Sbormík Severočeského musea 2, 1959, S. 207-237.

Karel Švehla, Současný stav a některé problémy zámeckýrch knihoven /Der gegenwärtige Zustand und einiige Probleme der Schloßbibliotheken/. In: Knihovmík 9, 1964, S. 239-242.

Dalibor Balcar, Pražské klášterní knihovny spravované Státtní knihovnou ČSSR - Universitní knihovnou v Praze /Prager Klosterbibliotheken in der Verwaltung der Staatsbibliothek der ĆSSR - Universitätsbibliothek Prag/. In: Ročenka Státní knihovny ČSSR v Praze 1965, S. 60-63.

František Horák, Klášterní knihovny v českých zerních /K'losterbibliotheken in den böhmischen Ländern/. In: Knihovna, Vèdecko-theoretický sborník 6, 1966, S. 219-270.

Vladislav Dokoupil, Dèjiny moravských klášterních knihoven ve správě Universitní knihovny v Brně /Geschichte der mährischen Klosterbibliotheken in der Verwaltung der Universitätsbibliothek Brno/. Brno, Universitní knihovna 1972. $379 \mathrm{~S}$. 
Jitka Šimáková, Dvě desetiletí správy zámeckých knihoven Knihovnou Národního muzea /Zwei Jahrzehnte Verwaltung der Schloßbibliotheken durch die Bibliothek des Nationalmuseums Prag/. In: Sborník Národního muzea, Reihe C - Literární historie 19, 1974, ć. 1-2, S. 49-55.

Kvèta Cempírková, 100 let Státní vědecké knihovny v Českých Budējovicích / 100 Jahre Staatliche wissenschaftliche Bibliothek České Budējovice/. České Budējovice, Jihočeské nakladatelství 1986. $89 \mathrm{~S}$. /S. 70-74 Beilage 11. Historische Fonds - gibt einen Überblick über die kirchlichen Bibliotheken, die von der Staatlichen wissenschaftlichen Bibliothek České Budëjovice übernommen wurden/.

Jaroslav Vrchotka, Tricet let správy zámeckých a hradních knihoven v ČSR /Dreißig Jahre Verwaltung der Burg- und Schloßbibliotheken in der ČSR/. In: Sborník Národního muzea, Reihe C - Literární historie 29, 1987, S. 73-84.

Petr Mašek, Zahájení soupisu tisku 16. století v zámeckých knihovnách v Čechách a na Moravẽ /Der Beginn des Verzeichnens von Drucken des 16. Jahrhunderts in den Schloßbibliotheken Böhmens und Mährens/. In: Miscellanea oddēlení rukopisu a vzácných tisku 5, S. 165-178. Praha, SK ČSR 1988. 
Anmerkung: Die folgenden in unserer Beilage durch ein Sternchen bezeichneten Publikationen wurden in kleinen Auflagen als vervielfältigte Maschinenschriften veröffentlicht.

BAĎUROVÁ, Anežka - BRTOVÁ, Bohuslava: "Soupis tisku 16. století ve fondech ZK-ÚVI ČSAV /Verzeichnis der Drucke des 16. Jahrhunderts in den Fonds der Hauptbibliothek - Wissenschaftliches Informationszentrum der Tschechoslowakischen Akademie der Wissenschaften/. In: Vědecké informace ČSAV, Bibliografie 1. Praha, ZK-ÚVI ČSAV 19871988. Teil I-III. $462+223$ S. /786 Eintragungen/

BOHATCOVÁ, Mirjam: Vzácná sbírka publicistických a portrétních dokumentu $\mathrm{k}$ počátku tricetileté války /Eine kostbare Sammlung publizistischer und Portraits-Dokumente vom Beginn des Dreißigjährigen Krieges (Bibliothek des Nationalmuseums in Prag 102 A 1-199)/. In: Sborník Národního muzea v Praze, Reihe C - Literární historie XXVII, 1982, Nr. 1, S. 1-73. /198 Eintragungen/

ČERNÁ-ŠLAPÁKOVÁ, Marie Ludmila: Vzácné staré knihy ve Státní technické knihovnè v Praze /Rare alte Bücher in der Staatlichen Technischen Bibliothek Prag/. Praha, Státní pedagogické nakladatelství 1971. 344 S. /411 Eintragungen/

CHALOUPKA, Adolf: Divadelní Pragensia v drobných spisech Lobkovické knihovny /Theater - Pragensia in kleinen Schriften der Lobkowicz- Bibliothek/. In: Ročenka Universitní knihovny v Praze 1958, Praha 1959, S. 120-124. /ca. 30 Eintragungen/

CHALOUPKA, Adolf: Mimopražská teatralia $\mathbf{v}$ drobných spisech Lobkovické knihovny /Theatralia außer Prag in kleinen Schriften der Lobkowicz-Bibliothek/. In: Ročenka Universitní knihovny $\vee$ Praze 1959, Praha 1961, S. 106-119. /19 Eintragungen/ 
DOKOUPIL, Vladislav: * Katalóg slovacikálnych kníh do roku 1800 Univerzitnej knižnice v Brne /Katalog von Büchern mit slowakischem Bezug bis zum Jahre 1800 in der Universitätsbibliothek Brno/. Martin, Matica slovenská 1969. 230 S. /661 Eintragungen/

DOKOUPIL, Vladislav: * Soupis komenian Universitní knihovny v Brnè /Verzeichnis der Comeniana der Universitätsbibliothek Brno/. Brno, Universitní knihovna 1957. 112 S. /ca. 440 Eintragungen/

DOKOUPIL, Vladislav - VOBR, Jaroslav: * Soupisy tisku 16. století $\mathrm{z}$ fondu Universitní knihovny v Brnè. $10 \mathrm{sv}$. /Verzeichnis der Drucke des 16. Jahrhunderts aus den Fonds der Universitätsbibliothek Brno/ 10 Bde.:

Bd. 1: Vl. Dokoupil, Klášterní knihovna kapucínu v Brně /Die Bibliothek des Kapuzinerklosters in Brno/. Brno, Universitní knihovna 1955. 181 S. /522 Eintragungen/

Bd. 2: Vl. Dokoupil, Tisky 16. století $\mathrm{z}$ knihovny benediktinù v Rajhradè /Die Drucke des 16. Jahrhunderts aus der Bibliothek des Benediktinerklosters in Rajhrad/. Brno, Universitní knihovna 1959. $378 \mathrm{~S}$. /1219 Eintragungen/

Bd. 3: Vl. Dokoupil, Tisky 16. století z knihovny premonstrátu v Nové Ŕísi /Die Drucke des 16. Jahrhunderts aus der Bibliothek des Prämonstratenserklosters in Nová Ríše/. Brno, Universitní knihovna 1960. 123 S. /331 Eintragungen/

Bd. 4: Vl. Dokoupil, Tisky 16. stoletỉ z knihovny minoritu v Brnè /Die Drucke des 16. Jahrhunderts aus der Bibliothek des Minoritenklosters in Brno/. Brno, Universitní knihovna 1960. 87 S. /237 Eintragungen/

Bd. 5: Vl. Dokoupil, Tisky 16. století z knihovny augustiniánu na Starém Brnè /Die Drucke des 16. Jh. aus der Bibliothek des Augustinerklosters in Staré Brno/. Brno, Universitní knihovna 1963. Teil 1-2. 424 S. /1370 Eintragungen/ 
Bd. 6: Vl. Dokoupil - J. Vobr, Tisky 16. století v Universitní knihovnè v Brně /Die Drucke des 16. Jh. in der Universitätsbibliothek Brno/. Brno, Universitní knihovna 1970. Teil 1-3. $556+203$ S. /2106 Eintragungen/

Bd. 7: Vl. Dokoupil - J. Vobr, Tisky $16 . \quad$ století z knihoven dominikánu a kapucínu ve Znojmè, křižovníku na Hradišti u Znojma a piaristu v Mikulovẽ /Die Drucke des 16. Jh. aus den Bibliotheken der Dominikaner und Kapuziner in Znojmo, der Kreuzherren in Hradiště bei Znojmo und der Piaristen in Mikulov/. Brno, Universitni knihovna 1972. 312 S. /839 Eintragungen/

Bd. 8: Vl. Dokoupil - J. Vobr, Tisky 16. století z knihoven františkánu v Dačicích a $\mathrm{v}$ Moravské Tŕebové, minoritú v Jihlavẽ a biskupského alumnátu v Brnè /Die Drucke des 16. Jh. aus den Bibliotheken der Franziskaner in Dačice und Moravská Třebová, der Minoriten in Jihlava und des bischöflichen Alumnats in Brno/. Brno, Universitní knihovna 1973. $236 \mathrm{~S}$. /543 Eintragungen/

Bd. 9: J. Vobr - Vl. Dokoupil, Tisky 16. století z knihovny hrabat Chorinských ve Veselí nad Moravou a $z$ knihovny bývalého jezuitského gymnasia $\mathbf{v}$ Brnè /Die Drucke des 16. Jh. aus der Bibliothek der Grafen Chorinský in Veselí nad Moravou und aus der Bibliothek des ehemaligen Jesuitengymnasiums in Brno/. Brno, Universitní knihovna 1977. $395 \mathrm{~S}$. /887 Eintragungen/

Bd. 10: J. Vobr, Tisky 16. století ve Státní vědecké (dríve Universitní) knihovnè v Brnè. Př́rúrtky 1968-1978 /Die Drucke des 16. Jh. in der Staatlichen wissenschaftlichen Bibliothek, früher Universitätsbibliothek Brno. Zuwächse aus den Jahren 1968-1978/. Brno, Státní vědecká knihovna 1981. Teil 1-2. 573 S. /1286 Eintragungen/ 
DOKOUPIL, Vladislav - TELEC, Vladimír: * Hudebni staré tisky ve fondech Universitní knihovny v Brnè /Alte Drucke der Musikalien in den Fonds der Universitätsbibliothek Brno/. Brno, Universitní knihovna 1975. 250 S. / 676 Eintragungen/

EDERER, Antonín: Technická bohemika v knihovnè Národního technického musea. Vzácné a nejstarší tisky $\mathbf{k}$ dèjinám technické práce $v$ ČSR /Technische Bohemica in der Bibliothek des Nationalen Technischen Museums. Rare und älteste Drucke zur Geschichte der technischen Arbeit in der CSR/. In: Sborník Národního technického musea 1955, S. 133-144. /92 Eintragungen/

FLODROVÁ, Milena - NOSEK, Bedřich: Auswahlkatalog hebräischer Drucke Brünner Provenienz. Judaica Bohemiae 11, 1975, Nr. 2, S. 83-104. /37 Eintragungen aus den Sammlungen des Staatlichen jüdischen Museums in Prag/

HAMANOVÁ, Pavlína: Francouzská ilustrovaná kniha XV.XIX. stol. v Národní a universitní knihovně v Praze /Das französische illustrierte Buch des XV.-XIX. Jh. in der National- und Universitätsbibliothek in Prag/. In: Český bibliofil 9, 1937, S. 231-52. /Eintragungen kontinuierlich im Text/

JAROLÍM, Miroslav: * Katalog starých tisku knihovny Astronomického ústavu CSAV / Katalog der alten Drucke der Bibliothek des Astronomischen Instituts der Tschechoslowakischen Akademie der Wissenschaften/. In: Scripta astronomica 1. Praha, Astronomický ústav ČSAV 1986. 312 S. /204 Eintragungen/

JENÍK, František: Nová humanistická polonika v Universitní knihovnè v Praze /Neue humanistische Polonica in der Universitätsbibliothek Prag/. In: Ročenka Universitní knihovny v Praze 1956, Praha 1958, S. 109-134. /31 Eintragungen/ 
JOHANIDES, Josef - KNEIDL, Pravoslav: Výběr z tiskư mladovožické knihovny. Prvotisky a paleotypyy /Auswahl aus den Drucken der Schloßbibliothelk von Mladá Vožice. Wiegendrucke und Paläotype/'. In: Sborník Národního musea v Praze, Reihe C - Literární historie VI, 1961, S. 119-187. /29:5 Eintragungen/

KARÁSKOVÁ, Riužena: * Dílo Jana Amose Komenského ve fondu Státní vědecké knihovny v Olomoucĩ. Bibliografie za léta 1624-1987 /Das Werk von Jan Amos Komenský in Fonds der Staatlichen wissenschaftlichen Bibliothek Olomouc. Bibliographie für die Jahre 1624-1987 /. Olomouc, Státní vědecká knihovna 1988. 77 S. /319 Eintragungen/

KAŠPAR, Oldřich: * Soupis španēlských a portugalských tiskủ bývalé pražské Lobkovické knihovny, nyní deponovaných ve Státní knihovnè ČSR v Praze /Verzeichnis der spanischen und portugiesischen Drucke der ehemaligen Prager Lobkowicz-Bibliothek, jetzt deponiert in der Staatsbibliothek der ČSR Prag/. Praha, Státní knihovna ČSR 1984. 183 S. /121 Eintragungen/

KAŠPAR, Oldřich: * Soupis španēlských tiskủ bývalé zámecké knihovny v Roudnici nad Labem, nyní deponovaných ve Státní knihovně ČSR v Praze /Verzeichnis der spanischen Drucke der ehemaligen Schloßbibliothek in Roudnice nad Labem, jetzt deponiert in der Staatsbibliothek Prag/. Praha, Státní knihovna ČSR 1983. 387 S. /491 Eintragungen/

KNEIDL, Pravoslav und Kollektiv: Teatralia zámecké knihovny $z$ Radenína / Theatralia der Schloßbibliothek aus Radenín/. Praha, Národni museum 1962-1969. Teil I-III. /4835 Eintragungen/ 
KOTT, Ludwig: Die Inkunabeln und Frühdrucke bis 1536 , sowie andere Bücher des XVI. Jahrhunderts aus der ehemaligen Piaristenbibliothek in Leipnik. In: Jahresbericht der deutschen Landes-Oberrealschule in Leipnik 7, 1906, S. 3-47; 8, 1907, S. 3-53. /103 Eintragungen/

LIFKA, Bohumír: * Valdštejnská knihovna na zámku v Doksech. I. Soupis starých tiskí $(A-M)$. II. Soupis starých tisku krom beletrie $(\mathrm{N}-\check{\mathrm{Z}})$. Staré tisky krásného písemnictví (A-Ž) /Die Bibliothek der Familie Valdštejn in Doksy. I. Verzeichnis der alten Drucke (A-M). II. Verzeichnis der alten Drucke außer der schönen Literatur $(\mathrm{N}-\mathrm{Z})$. III. Alte Drucke der schönen Literatur (A-Ž) /. In: Vèdecké informace ČSAV 1969, Suplement 2-4. Praha, ZKÚVI ČSAV 1969; Vèdecké informace ČSAV 1970, Suplement 2-4. Praha, ZK-ÚVI ČSAV 1970. 386 S. /1728 Eintragungen/

MACHÁČEK, Fridolín: Prvotisky a staré tisky Městského historického musea a plzeňské knihovnictví /Wiegendrucke und alte Drucke des Städtischen historischen Museums und das Pilsner Bibliothekswesen/. Plzeñ, Městské historické museum 1926. 35 S. /59 Eintragungen/

NESPĚCHAL, Zdeněk: Staré české a slovenské tisky ve fondech muzeí v Rychnově $n$. Kn. a v Dobrušce /Alte tschechische und slowakische Drucke in den Fonds des Museums in Rychnov nad Kněžnou und in Dobruška/. In: Acta musei Rychnoviensis 2. Rychnov nad Kněžnou, Okresní muzeum Orlických hor 1983. 178 S. /549 Eintragungen/ 
NOSEK, Bedřich: Auswablkatalog hebräischer Drucke Pragłer Provenienz aus dem 18. Jahrhundert in den Sammlungen des Staatlichen jüdischen Museums in Praug. III. Teil: 1700-1799. In: Judaica Bohemiae 1.3, 1977, S. 96-120; Judaica Bohemiae 14, 1978, S. 35 58. /125 Eintragungen/

NOSEK, Bedřich: Katalog ausgewählter hebräischer Druclke Prager Provenienz aus der Sammlung des Staautlichen jüdischen Museums in Prag. II. Teil: D)ie Buchdruckerei der Familie Bak. Die Buchdruckerei des Abraham ben Schimcon Heida, genannt Lennberger. In: Judaica Bohemiae 11, 1975, S. 29-513. /47 Eintragungen/

NOSEK, Bedřich: Katalog mit der Auswahl hebräischer Druckke Prager Provenienz. I. Teil: Drucke der Gersonideen im 16. und 17. Jahrhundert. In: Judaica Bohemiae 10, 1974, S. 13-41, 64-65. /51 Eintragungen/

POŠTOLKA, Milan: Libreta strahovské hudební sbírky /Libretti der Musiksammlung Strahov/. In: Misceellanea musicologica 25-26. Praha, Universita Karliova 1973, S. 79-149. /99 Eintragungen/

PUMPRLA, Václav: Katalóg slovacikálnych kníh do roku 1800 Štátnej vedeckej knižnice v Olomouci /Katalıog von Büchern mit slowakischem Bezug bis zum Jaihr 1800 der Staatlichen wissenschaftlichen Bibliotheek in Olomouc/. Martin, Matica slovenská 1974. 412 S. /575 Eintragungen/

PUMPRLA, Václav: "Soupis starých tiskủ ve fonderch Státní vědecké knihovny v Olomouci /Verzeichnis der alten Drucke in den Fonds der Staatlichen wissenschaftlichen Bibliothek in Olomouc/: 
I. Tisky vydané na území Čech a Moravy v letech $1501-1800$ /Auf dem Territorium von Böhmen und Mähren in den Jahren 1501 - 1800 erschienene Drucke/. Olomouc, Státní vědecká knihovna 1974 - 1979. 12 Bde. /5277 Eintragungen/

II./1 Krakovské tisky vydané v letech 1501 - 1800 /In den Jahren 1501 - 1800 erschienene Krakauer Drucke/. Olomouc, Státní vědecká knihovna 1979. $124 \mathrm{~S}$. /243 Eintragungen/

II./2 Tisky Budyšína, Cvikova, Dráżdan, Zhořelce a Žitavy 1501 - 1800 /Drucke aus Bautzen, Zwickau, Dresden, Görlitz und Zittau von 1501 - 1800/. Olomouc, Státní vědecká knihovna 1981. $189 \mathrm{~S}$. /347 Eintragungen/

II./3 Vratislavské tisky $z$ let $1501-1800$ /Breslauer Drucke aus den Jahren 1501 - 1800/. Olomouc, Státní vědecká knihovna 1982. 187 S. /457 Eintragungen/

III. Tisky 2 lékařství a príbuzných oboru 2 let 1501 1800 /Drucke aus dem Bereich der Medizin und verwandter Disziplinen aus den Jahren 1501 1800/. Olomouc, Státní vědecká knihovna 19801988. 6 Bde. /4405 Eintragungen/

IV. Hispanika a iberoamerikána 1501 - 1800 (za spolupráce Oldřicha Kašpara) /Hispanika und Iberoamerikana 1501-1800 (unter Mitarbeit von Oldřich Kašpar)/. Olomouc, Státní vědecká knihovna 1981. $333 \mathrm{~S}$. /705 Eintragungen/

PUMPRLA, Václav: Soupis starých tisku ve sbírce Okresního vlastivědného muzea ve Frýdku-Místku /Verzeichnis der alten Drucke in der Sammlung des Kreisheimatmuseums in Frýdek-Místek/. Frýdek-Místek, Okresní vlastivědné muzeum 1985. $172 \mathrm{~S} . / 537$ Eintragungen/ 
SLÁDEK, Jiří: *Rossika 16. - 18. století v zámeckyúrch a palácových knihovnách $v$ Čechách a na Mora:vè /Rossika des 16. - 18. Jh. in Schloß- und Palastibibliotheken Böhmens und Mährens/. Praha, Státiní knihovna ČSR 1977. 193 S. /307 Eintragungen/

STURM, Heribert: Die Bücherei der Lateinschule zu St. Joachimsthal. St. Joachimsthal, Stadtmuserum 1929. 196 S. /353 Eintragungen/. 2. Au:fl. Stuttgart 1964.

ŠIMÁKOVÁ, Jitka - MACHÁČKOVÁ, Eduarda: Teatralia ziámecké knihovny v Českém Krumlovè /Theatrallia der Schloßbibliothek in Český Krumlov/. Prahia, Národní muzeum 1976. Teil I-III. /2413 Eintragungen/

ŠIMÁKOVÁ, Jitka - MACHÁČKOVÁ, Eduarda: * Teatraliia zámecké knihovny $\mathrm{z}$ Kr̈imic /Theatralia dier Schloßbibliothek in Kr̆imice/ Praha, Národ:ní muzeum 1970. Teil I-II. /1880 Eintragungen/

ŚTÉPÁN, Václav: * Teatralia v zámecké knihovnè na Kačině. Výbèrový soupis /Theatralia der Schloßbibliotheek in Kačina. Auswahlverzeichnis/. Praha, Scénografický ústav 1973. 164 S. /682 Eintragungen/

TELEC, Vladimír: Staré tisky dēl českých skladatelu 1.8. století v Universitní knihovně v Brně /Alte Drucke der Werke von tschechischen Komponisten dies 18. Jahrhunderts in der Universitätsbibliothek in Brno/. Praha, Státní pedagogické nakladatelství 1969. 161 S. /552 Eintragungen/

TRAPP, Moriz - SCHRAMM, Wilhelm: Catalog der Bibliothek des Franzens-Museums der k.k. mähr. schless. Gesellschaft zur Beförderung des Ackerbaues, der Natur- und Landeskunde. Brünn, Verlag der k. kk. mähr. schles. Gesellschaft 1864-1896: 
Heft I-VIL Alphabetischer Theil und Nachtrag I-III. Brünn 1864-1878. $538 \mathrm{~S}$.

Heft VIII. Fachlicher Theil. Brünn 1879. $157 \mathrm{~S}$.

Heft IX-/XIII/. Nachtrag IV-VIII. Brünn 1884-1896. 40, 34, $24,36,112 \mathrm{~S}$.

/Alle Hefte insgesamt 16241 Eintragungen/

URBÁNKOVÁ, Emma - WIŽĎÁLKOVÁ, Bedřiška: Bohemika $z$ Městské knihovny v Žitavě ve fondu Státní knihovny ĊSR - Universitní knihovny. Soupis státního daru Nèmecké demokratické republiky /Bohemica aus der Stadtbibliothek Zittau in Fonds der Staatsbibliothek der CSR - Universitätsbibliothek. Verzeichnis des Staatsgeschenks der Deutschen Demokratischen Republik/. Praha, Státní pedagogické nakladatelství 1971. 122 S. /ca. 440 Eintragungen/

URBÁNKOVÁ, Emma: Rukopisy a vzácné tisky pražské Universitní knihovny /Handschriften und rare Drucke der Prager Universitätsbibliothek/. Praha, Státní pedagogické nakladatelství 1957. 111 S. /497 Eintragungen/

VACINOVÁ, Jana: * Zámecká knihovna v Opočně /Die Schloßbibliothek in Opočno/. Hradec Králové, Kruh 1971. 64 S. /ca. 110 Eintragungen kontinuierlich im Text/

VESELSKÁ, Jiřina: * Soupis kramářských písní ve sbírce Okresního vlastivědného muzea ve Frýdku-Místku /Verzeichnis der Bänkellieder in der Sammlung des Kreisheimatmuseums in Frýdek-Mistek/. In: Katalogy a soupisy sbírek Nr. 1. Frýdek-Místek, Okresní vlastivědné muzeum 1982. 281 S. /1045 Eintragungen/

VLČKOVÁ, Ludmila: * Benediktinská klášterní knihovna v Broumovẽ /Die Bibliothek des Benediktinerklosters in Broumov/. Hradec Králové, Kruh 1969. $86 \mathrm{~S}$. /182 Eintragungen/ 
VOBR, Jaroslav: * Soupis jihlavských tisků českých knížek lidıového čtení a populárnè naučné literatury z 18. a 1:9. století /Verzeichnis der Jihlavaer Drucke von tschiechischen Volksbüchern und populärwissenschaftllicher Literatur aus dem 18. und 19. Jh./. Jihlavia, Muzeum Vysočiny - Okresní knihovna 1969. 128 iS. /163 Eintragungen/

VOBR, Jaroslav: * Soupis knížek lidového čtení z fondủ Universitní knihovny v Brně /Verzeichnis der Volksbücher aus den Fonds der Universitätsbibliothek Brno/. Brno, Universitní knihovna 1973. 165 iS. /276 Eintragungen/

VOBR, Jaroslav: * Soupis postinkunábulí (tisku z let 15011520) z fondu Státní vèdecké knihovny v Brmè /Verzeichnis von Postinkunabeln (Drucke aus deen Jahren 1501-1520) aus den Fonds der Staatlicheen wissenschaftlichen Bibliothek Brno/. Brno, Stát:ní vědecká knihovna 1985-1988. Bd. 1-4 / A-Z, 10888 Eintragungen/. Bd. 5 (Register) 1989.

VRCHOTKA, Jaroslav und Kollektiv: Knihovna Bohuslava Duška /Die Bibliothek Bohuslav Dušeks/. In: Sborrník Národního muzea v Praze, Reihe C - Literární historie XXIII, 1978, Nr. 1-4. 300 S. /3199 Werke/

-VÝBĚr 2 prírústku starých tiskủ /Auswahl aus den Zuwächsen an alten Drucken, Staatsbibliothek dier ČSR/:

Num. 1: Wiždálková, Bedřiška: Slovenika a bohemika. Praha, Státní knihovna ČSR. s.a. /unpaginiert, 95 Eintragungen/

Num. 2: Wiždálková, Bedřiška: XVI. století /XVI. Jahrhundert/. Praha, Státní knihovna ČSR s.a. /unpaginiert, 114 Eintragungen/

Num. 3: Wiždálková, Bedriška: Vzácné tisky zednářské /Rare Freimaurerdrucke/. Praha, Státní knihovna ČSR s.a./ unpaginiert, 343 Eintragungen/ 
Num. 4: Wiždálková, Bedřiška: Bohemika a slovenika. Praha, Státní knihovna ČSR 1970. /unpaginiert, 199 Eintragungen/

Num. 5: Kulišek, Vladimír: Cizojazyčná bohemika /Fremdsprachige Bohemica/. Praha, Státní knihovna ČSR 1971. 55 S. /186 Eintragungen/

Num. 6: Kulíšek, Vladimír: Cizojazyčná bohemika a slovacika /Fremdsprachige Bohemica und Slovacica/. Praha, Státní knihovna ČSR 1972. 77 S. /200 Eintragungen/

Num. 7: Kulišsek, Vladimír: Cizojazyčná bohemika a slovacika /Fremdsprachige Bohemica und Slovacica/. Praha, Státní knihovna ČSR 1973. 80 S. /200 Eintragungen/

Num. 8: Kulíšek, Vladimír - Pokorný, Pavel: Cizojazyčná bohemika /Fremdsprachige Bohemica/. Praha, Státní knihovna ČSR 1981. 33 S. /84 Eintragungen/

Num. 9: Wiždálková, Bedřiška: Bohemika a slovenika. Praha, Státní knihovna ČSR 1982. /unpaginiert, 86 Eintragungen/

Num. 10: Wiždálková, Bedřiška: Skryté bohemikální poklady /Verborgene bohemikale Schätze/. Praha, Státní knihovna ČSR 1983. 7, 100 S. /98 Eintragungen/

*VÝBĚROVÝ soupis zajímavých starých tiskỉ z fondu Vèdecké a lidové knihovny $\mathbf{v}$ Liberci /Auswahlverzeichnis interessanter alter Drucke aus den Fonds der Wissenschaftlichen und Volksbibliothek in Liberec/. In: Publikace VLK Liberec, Reihe A, Bibliografie Nr. 85. 48 S. /138 Eintragungen/ 


\section{Register}

Adam von Veleslavín, Daniel 2, 3

Adauctus a S. Germano s. Voigt, Mikuláš

Arbour, Roméo 15

Archiv der Karlsuniversität s. Archiv Univerzity Karlovy, Praha

Archiv Univerzity Karlovy (Archiv der Karlsuniversität), Praha 17

Augustiner, Staré Brno (heute: Státní vědecká knihovna, Brno) 25

Badurová, Anežka 11, 18, 20, 24

Bak, Familie 30

Balbín, Bohuslav 2, 3, 18

Balcar, Dalibor 22

Bautzen (Budyšín) 17, 31

Bayerische Staatsbibliothek, München 15

Benediktiner, Broumov (heute: Státní vědecká knihovna, Hradec Králové) 33

-, Rajhrad (heute: Státní vědecká knihovna, Brno) 25

Bezděk, Karel 8

Bibliografie cizojazyčných bohemikálních tiskư z let 1501$180011,12,13,14,15,17$

Bibliothek des Astronomischen Instituts s. Knihovna Astronomického ústavu

- Bohuslav Dušeks (heute: Knihovna Národního muzea, Praha) 34

- des Franzens-Museums, Brünn (heute: Státní oblastní archiv, Brno) 32

- der Grafen Chorinský in Veselí nad Moravou (heute:

Státní vědecká knihovna, Brno) 26

- des Jesuitengymnasiums, Brünn (heute: Státní vědecká knihovna, Brno) 26 
- der Lateinschule zu St. Joachimsthal s. Bücherei

- s. auch Augustiner..., Bayerische Staatsbibliothek..., Benediktiner..., Bischöfliches Alumnat..., Dorminikaner..., Franziskaner..., Herzog August Bibliothek..., Kapuziner..., Klosterbibliotheken..., Knihovna..., Kreuzherren..., Lobkowicz-Bibliothek..., Mèstské historické muzeum..., Minoriten..., Museum..., Okresní vlastivědné muzeum..., Pfarrbibliotheken..., Piaristen..., Prämonstratenser..., Schlobbibliothek(en)..., Státní knihovna...., Státní technická knihovna..., Státní vědecká knihovna...., Státní židovské muzeum..., Strahovská knihovna...., Vèdecká a lidová knihovna..., Základní knihovna...

Bílá hora (Weißer Berg) 9, 16, 18

Bischöfliches Alumnat, Brünn (heute: Státní vědecká knihovna, Brno) 26

Bohatcová, Mirjam 11, 17, 21, 24

Böhmen 1, 2, 5, 6, 9, 12, 14, 15, 16, 18, 20, 21, 22, 23, 31, 32

Bok, Václav 2

Břeňová, Vèra 4

Bresłau s. Wroclaw

Brno (Brünn) 3, 4, 22, 25, 26, 27, 32, 34

Broumov 33

Brożek, Ludwik 5

Brtová, Bohuslava 11, 18, 24

Brünn s. Brno

Bücherei der Lateinschule zu St. Joachimsthal (heute: Okresní vlastivědné muzeum, Karlovy Vary) 32

Budyšín s. Bautzen

Cempírková, Květa 23

Černá-Šlapáková, Marie Ludmila 24

Cerroni, Jan Petr 3, 4

České Budějovice 23

Československá akademie vèd (ČSAV, Tschechoslowakiscte Akademie der Wissenschaften), Praha 8 
Československo (Tschechoslowakei) 13, 21

Český Krumlov 32

Chaloupka, Adolf 24

Chorinský, Grafen 26

Collinus, Matouš 8

Comenius, Jan Amos s. Komenský, Jan Amos

Corsten, Severin 21

ČSAV, s. Československá akademie vèd, Praha

Cunradus, Johannes Henricus 4, 5

Cuprová, Ludmila 17

Cvikov s. Zwickau

Dačice 26

Dlabač, Jan Bohumír 3, 4

Dobrovský, Josef 3, 4

Dobruška 29

Dokoupil, Vladislav 22, 25, 26, 27

Doksy 29

Dominikaner, Znojmo (heute: Státní vědecká knihovna, Brno) 26

Dráždany s. Dresden

Dresden (Dráżdany) 17, 31

Dubravius, Jan 6

Dušek, Bohuslav 34

Ederer, Antonín 27

Erber, Bernard 3, 4

Flodrová, Milena 27

Forster, Leonard 13

Frankfurt/Oder 4 
Franziskaner, Dačice (heute: Státní vědecká knihovmia, Brno) 26

-, Moravská Třebová (heute: Státní vědecká knihovmaa, Brno) 26

Frinta, Antonín 5

Frisius, Ioannes Iacobus 2

Frýdek-Místek 31, 33

Fuchs, Reimar Walter 21

Fueldener, Johannes Jakob 4, 5

Gelenius, Zikmund 6

Gersoniden, Familie 30

Gesamtkatalog der Wiegendrucke 7

Gesner, Konrad 2

Glatzer Gebiet 1, 4, 5, 16

Görlitz (Zhořelec) 4, 5, 17, 31

Göttingen 15

Hagecius, Tadeáš s. Hájek, Tadeáš

Hájek (Hagecius), Tadeáš 6

Hamanová, Pavlína 27

Hanuš, Ignác Jan 5

Hauptbibliothek - Wissenschaftliches Informationszentrum dier

ČSAV s. Základní knihovna - Ústředí vèdeckých informací ČSAV, Praha

Hejnic, Josef 2, 4, 9

Hejnová, Miroslava 21

Henelius, Nicolaus 4, 5

Herzog August Bibliothek, Wolfenbüttel 15

Hierowski, Zdisław 5

Horák, František 7, 11, 22

Hrabák, Josef 6

Hradiště bei Znojmo 26 
Hrdina, Karel 5, 8, 9, 10, 11, 15

Hussiten 1

Iaenichius, Petrus 5

Iessenius, Ioannes 6

Irmscher, Johannes 6

Jáchymov (Joachimsthal, Sankt Joachimsthal) 32

Jäger, Johannes 17

Jarolím, Miroslav 27

Jeník, František 27

Jesuiten 2, 4, 16

Jesuitengymnasium, Brünn (heute:Státní vědecká knihovna, Brno) 26

Jihlava 26,34

Jireček, Josef $6,7,8,14$

Joachimsthal s. Jáchymov

Johanides, Josef 28

Jungmann, Josef $5,6,7,14$

Kábrt, Jiři 4

Kačina 32

Kapuziner, Brünn (heute: Státní vẽdecká knihovna, Brno) 25

-, Znojmo (heute: Státní vědecká knihovna, Brno) 26

Karásková, Riužena 28

Karlsuniversität Prag s. Univerzita Karlova, Praha

Kašpar, Oldriich 28, 31

Klosterbibliotheken, in den böhmischen Ländern 22

- in Mähren 22

- in Prag 22

Knauthe, Chrístian 5

Kneidl, Pravoslav 28 
Knihopis českých a slovenských tiskủ od doby nejstarší až do konce XVIII. století 2, 4, 7, 8, 10, 11, 12,13, 14, 17

Knihovna Astronomického ústavu ČSAV (Bibliothek des Astronomischen Instituts der ČSAV), Praha 27

- Národního muzea (Bibliothek des Nationalmuseums), Praha 8, 23, 24

- Národního technického muzea (Bibliothek des nationalen technischen Museums), Praha 27

Kocowski, Bronisław 5

Komenský (Comenius), Jan Amos 2, 6, 18, 25, 28

Koniás, Antonín 4

Kott, Ludwig 29

Krakau s. Kraków

Kraków (Krakau) 4, 31

Kreisheimatmuseum Frýdek-Místek s. Okresní vlastivědné muzeum, Frýdek-Místek

Kreuzherren, Hradiště bei Znojmo (heute: Státní vědecká knihovna, Brno) 26

Křimice 32

Kristeller, Paul 13

Kropilák, Miroslav 16

Kulíšek, Vladimír 35

Kunze, Pètr 5

Lausitz 1, 3, 4, 5, 6, 13, 16, 18

Leipnik s. Lipník nad Bečvou

Leipzig 4

Lemberger, Abraham ben Schimon Heida 30

Liberec 35

Lifka, Bohumír 21, 22, 29

Lipník nad Bečvou (Leipnik) 29

Lobkowicz-Bibliothek, Prag (heute: Státní knihovna ČSR, Praha) 24, 28 
-, Roudnice nad Labem (heute: Státní knihovna ČSR, Praha) 28

Ludvikovský, Jaroslav 16

Lupáč (Lupacius), Prokop 2, 3

Lupacius, Prokop s. Lupáč, Prokop

Macháček, Fridolín 29

Macháčková, Eduarda 32

Mähren 1, 2, 5, 6, 9, 12, 14, 16, 17, 18, 20, 21, 22, 23, 31, 32

Martínek, Jan 9, 10

Mašek, Petr 23

Městské historické muzeum (Städtisches historisches Museum, heute: Západočeské muzeum), Plzeñ 29

Mikulov 26

Minoriten, Brünn (heute: Státní vědecká knihovna, Brno) 25

-, Jihlava (heute: Státní vědecká knihovna, Brno) 26

Mladá Vožice 28

Moravská Třebová 26

München 15

Museum in Dobruška 29

- in Rychnov nad Kněžnou 29

- des tschechischen Schrifttums s. Strahovská knihovna

Památniku národního písemnictví, Praha

Národní muzeum (Nationalmuseum), Praha 22, 24

Nationalmuseum, Prag s. Národní muzeum, Praha

National- und Universitätsbibliothek, Prag s. Státní knihovna ČSR, Praha

Nespěchal, Zdeněk 29

Niederlausitz s. Lausitz

Niederschlesien s. Schlesien

Nordböhmen s. Böhmen 
Nosek, Bedřich 27, 30

Nová Riše 25

Oberlausitz s. Lausitz

Oberschlesien s. Schlesien

Ogrodziński, Wincenty 5

Okresní vlastivědné muzeum (Kreisheimatmuseum), FrýdekMístek 31, 33

Olmütz s. Olomouc

Olomouc (Olmütz) 2, 4, 17, 28, 30

Opočno 33

Otto, Jan 8

Pelcl, František Martin 3

Pfarrbibliotheken in Nordböhmen 22

Piaristen, Leipnik (heute: Okresní archiv, Přerov) 29

-, Mikulov (heute: Státní vědecká knihovna, Brno) 26

Pilsen s. Plzeñ

Pitter, Josef Bonaventura 3

Plzeñ (Pilsen) 29

Pokorný, Pavel 35

Poštolka, Milan 30

Prämonstratenser, Nová Ríśs (heute: Státní vědecká knihovna, Brno) 25

Prag s. Praha

Prager Universität s. Univerzita Karlova, Praha

Praha (Prag) 1, 2, 4, 12, 15, 24, 28, 30

Pumprla, Václav 17, 30, 31

Purš, Jaroslav 16

Radenín 28

Rajhrad 25 
Ribay Jiří 3

Richterová, Alena 18

Roudnice nad Labem 28

Rudolf II. 1, 15, 18

Rukovět̆ humanistického básnictví v Čechách a na Moravě 9 , $10,11,13,14,17$

Rukověť $\mathrm{k}$ písemnictví humanistickému, zvláště básnickému, $\mathrm{v}$

Čechách a na Moravè $8,9,11$

Ryba, Bohumil 8, 11

Rychnov nad Kněžnou 29

Ryšavá, Eva 8

Sankt Joachimsthal s. Jáchymov

Schlesien 1, 4, 5, 6, 13, 16, 18

SchloBbibliothek, Český Krumlov 32

-, Doksy 29

-, Kačina 32

-, Kr̈imice 32

-, Mladá Vožice 28

-, Opočno 33

-, Radenín 28

-, Roudnice nad Labem 28

SchloBbibliotheken in Böhmen und Mähren 21, 22, 23, 32

-, in der CSR 23

Schramm, Wilhelm 32

Schwamberger, Leopold 4

Seibt, Ferdinand 13, 14

Šèn, Franc 5

Šimák, Josef Vítězslav 5

Simáková, Jitka 23, 32

Simler, Ioasias 2

Škarka, Antonín 16 
Sládek, Jiří 32

Šolta, Jan 5

Sorben 5

Staatliches jüdisches Museum in Prag s. Státní židovskeé muzeum $v$ Praze

Staatliche technische Bibliothek, Prag s. Státní technická knihovna, Praha

Staatliche wissenschaftliche Bibliothek,... s. Státní vědeckiá knihovna

Staatsbibliothek der ČSR, Prag s. Státní knihovna ČSR, Prahia Stadtbibliothek, Zittau 33

Städtisches historisches Museum, Pilsen s. Mĕstské historickié muzeum, Plzeñ

Státní knihovna ČSR (Staatsbibliothek der ČSR, früher National- und Universitätsbibliothek), Praha 7, 17, 18, 22, 27, $2833,34,35$

Státní technická knihovna (Staatliche technische Bibliothek)), Praha 24

Státní vědecká knihovna (Staatliche wissenschaftliche Biblio)thek, früher Universitätsbibliothek), Brno 22, 25, 26, 27, 32,34

Státní vědecká knihovna (Staatliche wissenschaftliche Bibliothek), Ceské Budējovice 23

- , Olomouc 17, 28, 30

Státní židovské muzeum (Staatliches jüdisches Museum), Prah.a 27,30

Staub, Kurt-Hans 21

Staudius, Christophorus 5

Štèpán, Václav 32

Strahovská knihovna Památniku národního písemnictwí (Museum des tschechischen Schrifttums), Praha 4, 30

Stránský, Pavel 2

Středovský, Jan Jiří 3

Sturm, Heribert 32 
Švábenský, Mojmír 4

Švehla, Karel 22

Telec, Vladimír 27, 32

Tobolka, Zdeněk Václav 7, 11

Tomek, Wácslaw Wladiwoj 5

Trapp, Moriz 32

Truhlár̆, Antonín 8, 9, 10,11, 15

Tschechoslowakei s. Československo

Tschechoslowakische Akademie der Wissenschaften s. Československá akademie věd

Ungar, Karel Rafael 3

Universitätsbibliothek, Brno s. Státní vědecká knihovna, Brno -, Praha s. Státní knihovna ČSR, Praha

Univerzita Karlova (Karlsuniversität, Prager Universität), Praha 1, 2, 4, 9

Urban, Adam V. 4

Urbánková, Emma 7, 18, 21, 33

Vacinová, Jana 33

Valdštejn, Familie 29

Varcl, Ladislav 16

Vavroušková, Anna 22

Vèdecká a lidová knihovna $v$ Liberci (Wissenschaftliche und Volksbibliothek in Liberec) 35

Veleslavín, Daniel Adam von s. Adam von Veleslavín, Daniel

Veselí nad Moravou 26

Veselská, Jiřina 33

Vidmanová, Stanislava 18

Vlčková, Ludmila 33

Vobr, Jaroslav 26, 34 
Voigt, Mikuláš (Adauctus a S. Germano) 3

Voit, Petr 7

Vrchotka, Jaroslav 23, 34

\section{Weimar 15}

Weißer Berg s. Bílá hora

Westböhmen s. Böhmen

Wissenschaftliche und Volksbibliothek in Liberec s. Vědecká a lidová knihovna v Liberci

Wittenberg 4

Wiždálková, Bedrišska 4,33, 34, 35

Wladislaw Jagíello 9

Wolfenbüttel 15

Wolkan, Rudolf 13

Wroclaw (Breslau) 4, 17, 31

Základní knihovna - Ústředỉ vědeckých informací ČSAV (Hauptbibliothek - Wissenschaftliches Informationszentrum der ČSAV), Praha 11, 13, 24

Zalužanský von Zalužany, Adam 6

Zaremba, Jan 5

Zhořelec s. Görlitz

Zíbrt, Čeněk 8

Ziegetbauer, Magnoald 3

Žitava s. Zittau

Zittau (Žitava) 17, 31, 33

ZK - ÚVI ČSAV s. Základní knihovna - Ústředí vědeckých informací ČSAV, Praha

Znojmo 26

Zürich 2

Zwickau (Cvikov) 17, 31 
Bisher erschienen (im W.Schmitz Verlag, Gießen):

Band 1: Peter Thiergen

Turgenevs "Rudin" und Schillers "Philosophische Briefe".

(Turgenev Studien III)

1980, 66 S., broschiert, DM 19,80

Band 2: Bärbel Miemietz

Kontrastive Linguistik.

Deutsch-Polnisch 1965-1980

1981, 132 S., broschiert, DM 25,-

Band 3: Dietrich Gerhardt

Ein Pferdename

Einzelsprachliche Pointen und die Möglichkeiten ihrer Über setzung am Beispiel von A.P. Čechovs "Lošadinaja familija". 1982, 69 S., broschiert, DM 20,-

Band 4: Jerzy Kasprzyk

Zeitschriften der polnischen Aufklärung und die deutsch Literatur.

1982, 93 S., broschiert, DM 20.-

Band 5: Heinrich A.Stammler

Vasilij Vasil'evič Rozanov als Philosoph.

1984, 90 S., broschiert, DM 20.-

Band 6: Gerhard Giesemann

Das Parodieverständnis in sowjetischer Zeit.

Zum Wandel einer literarischen Gattung.

1983, 54 S., broschiert, DM 19,-

Band 7: Annelore Engel-Braunschmidt

Hebbel in Rußland 1840-1978.

Gefeierter Dichter und verkannter Dramatiker.

1985, 64 S., broschiert, DM 20,-

Band 8: Suzanne L.Auer

Borisav Stankovićs Drama "Koštana"

Übersetzung und Interpretation.

1986, 106 S., broschiert, DM 20,-

(im Otto Sagner Verlag, München):

Band 9: Peter Thiergen (Hrsg.)

Rudolf Bächtold zum 70. Geburtstag

1987, 107 S., broschiert, DM 22,- 
Band 10: A.S.Griboedov

Bitternis durch Geist

Vers-Komödie in vier Aufzügen. Deutsch von Rudolf Bäci told

1988, 101 S., broschiert, DM 20,-

Band 11: Paul Hacker

Studien zum Realismus I.S.Turgenevs

1988, 79 S., broschiert, DM 20,-

Band 12: Suzanne L. Auer

Ladislav Mñačko

Eine Bibliographie

1989, 55 S., broschiert, DM 16,-

Band 13: Peter Thiergen

Lavreckij als "potenzierter Bauer"

$\mathrm{Zu}$ Ideologie und Bildsprache in I.S.Turgenevs "Das Ade.: nest"

1989, 40 S. Text plus 50 S. Anhang, broschiert, DM 18,-

Band 14: Aschot R. Isaakjan

Glossar und Kommentare zu $V$. Astafjews "Der trauri"

Detektiv"

1989, 52 S., broschiert, DM 10,-

Band 15: Nicholas G. Žekulin

The Story of an Operetta: Le Dernier Sorcier

by Pauline Viardot and Ivan Turgenev

1989, 155 S., broschiert, DM 18,-

Band 16: Edmund Heier

Literary Portraits in the Novels of F. M. Dostoevskij

1989, 135 S., broschiert, DM 18,-

München 